\title{
Comparison of 63 different void fraction correlations for different flow patterns, pipe inclinations, and liquid viscosities
}

\author{
Lina Márquez-Torres ${ }^{1}$. Jhara Ochoa-Pineda ${ }^{1} \cdot$ Paula Pico $^{1} \cdot$ Juan Pablo Valdés ${ }^{1} \mathbb{D}$. Deisy Becerra ${ }^{1}$. Andrés Pinilla ${ }^{1}$. \\ Eduardo Pereyra ${ }^{2} \cdot$ Nicolás Ratkovich ${ }^{1}$
}

Received: 29 November 2019 / Accepted: 28 August 2020 / Published online: 13 September 2020

(c) Springer Nature Switzerland AG 2020

\begin{abstract}
Gas-liquid two-phase flow is commonly encountered in the oil industry, especially in transport pipelines. Thus, the correct prediction of operational parameters such as void fraction or pressure drop is necessary for the development of efficient processes and facility design. Nowadays, there are different studies focused on predicting the void fraction parameter with empirical correlations. This study was aimed at analyzing and comparing 63 different void fraction correlations in order to determine if there was a unique correlation capable of accurately predicting the void fraction for the different operational conditions of flow patterns, pipe inclinations, and liquid viscosity. For this reason, a database of 11,895 experimental points was used to compare the results against the different empirical correlations available in the literature and determine the best one using statistical analyses based on indicators, such as relative error, absolute average percent error, among others. It must be mentioned that the database was strictly filtered and divided depending on the flow pattern (i.e., slug, churn, bubbly, and annular), the different pipe inclinations (i.e., vertical, horizontal and inclined), and the liquid viscosities. The results showed that there was not a unique unified correlation to determine the void fraction accurately for the different operational conditions and fluid properties. However, the best correlations for each specific set of flow patterns, pipe inclinations, and intervals of liquid viscosities were determined according to the statistical indicators, the general assumptions of each correlation, and information reported in the literature. Moreover, it was possible to analyze and provide some recommendations for the patterns evaluated, taking into account that some specific cases require further study, as there was no correlation capable of providing reliable results for the prediction of void fraction.
\end{abstract}

Keywords Empirical correlations · Flow pattern · Statistical indicators · Two-phase flow · Void fraction · Viscosity

$\begin{array}{llll}\text { List of symbols } & E_{3} & \text { Percent standard deviation (\%) } \\ D & \text { Pipe diameter }(\mathrm{m}) & E_{4} & \text { Average error }(-) \\ L & \text { Pipe length }(\mathrm{m}) & E_{5} & \text { Absolute average error }(-) \\ \mu & \text { Viscosity }(\mathrm{Pa} \mathrm{s}) & E_{6} & \text { Standard deviation }(-) \\ \rho & \text { Density }\left(\mathrm{kg} / \mathrm{m}^{3}\right) & \mathrm{R}^{2} & \text { Determination coefficient }(-) \\ \varepsilon & \text { Void fraction }(-) & g & \text { Gravity acceleration }\left(\mathrm{m} / \mathrm{s}^{2}\right) \\ E_{1} & \text { Average percent error (\%) } & \theta & \text { Inclination angle }\left({ }^{\circ}\right) \\ E_{2} & \text { Absolute average percent error }(\%) & u_{s G} & \text { Gas superficial velocity }(\mathrm{m} / \mathrm{s})\end{array}$

Electronic supplementary material The online version of this article (https://doi.org/10.1007/s42452-020-03464-w) contains supplementary material, which is available to authorized users.

Juan Pablo Valdés, jp.valdes10@uniandes.edu.co| 'Department of Chemical Engineering, Universidad de Los Andes, Bogota, Colombia. ${ }^{2}$ McDougall School of Petroleum Engineering, The University of Tulsa, Tulsa, OK 74104, USA. 
$u_{s L} \quad$ Liquid superficial velocity $(\mathrm{m} / \mathrm{s})$

$u_{m} \quad$ Mixture velocity $(\mathrm{m} / \mathrm{s})$

Re Reynolds number (-)

Fr Froude number (-)

We Weber number (-)

$e_{R} \quad$ Relative error (-)

$e_{A} \quad$ Actual error (-)

$F_{R P} \quad$ Relative performance factor (-)

\section{Subscripts}

G/L Gas/liquid phase

$\mathrm{C} / \mathrm{M}$ Calculated/measured value

\section{Introduction}

Two-phase flow refers to the simultaneous flow of two phases of any solid, liquid, or gas [1]. Gas-liquid twophase flow is commonly encountered in the petroleum, nuclear, and process industry. Therefore, parameters such as the void fraction, pressure drop, or heat transfer need to be considered as operational and design parameters in these industrial processes [2], especially for pipeline transportation in the petroleum industry. Regarding the pipeline transportation of gas-liquid flow, several flow patterns can appear, and they take an active part in the prediction of the aforementioned parameters. The most common flow patterns are stratified, annular, bubbly, slug, plug, and churn flow, but this study focuses on bubbly, slug, annular, and churn flow specifically.

Bubbly flow is characterized by gas bubbles dispersed in the liquid. These bubbles are of different sizes and shapes (near spherical), and in horizontal pipes, they tend to be in the upper part of the pipe. Annular flow takes place when the gas has a high velocity, expelling the liquid from the center of the pipe, and it begins to flow near the walls. Additionally, elongated bubble flow occurs when the velocity of the gas increases, and large amplitude waves of bubbles are formed. Similarly, slug flow occurs when the void fraction increases and the bubbles coalesce, producing larger and elongated bubbles with liquid sections in between called slugs [3].

The appearance of different flow patterns depends on operational conditions such as flow rates and pipe inclinations, and its presence can influence the measurement and prediction of the void fraction. Void fraction is a fundamental parameter for the operation and design of facilities. Due to its importance, several empirical correlations have been developed for the prediction of this parameter from different disciplines such as nuclear, chemical, petroleum, and cooling engineering.

Several studies have analyzed the prediction capabilities of the empirical correlations on the void fraction. For example, Woldesemayat and Ghajar [1] made an extensive study compiling several empirical correlations to determine which ones have the best predictive capabilities; their results demonstrated that most of the correlations were inaccurate at handling different operational conditions and they suggested a newer, more robust and more reliable correlation.

In other studies, Parrales et al. [4] studied 50 different void fraction correlations to find the most appropriate ones for determining the heat transfer coefficient on evaporators, and determined that the most reliable ones were based on a drift flux formulation. On a separate research, Godbole et al. [5] analyzed more than 50 correlations for the prediction of the void fraction for vertical upward flow; the main results showed that the drift flux-based correlations had the best performance, and suggested that future correlations should be developed based on this formulation. Considering this, recently, Bhagwat and Ghajar [2] and Wang et al. [6] separately performed researches proposing new void fraction correlations based on a drift flux formulation, successfully out-performing other correlations.

In this context, the purpose of this study is to analyze 63 different empirical correlations in order to suggest the most appropriate one for different pipe inclinations, the presence of different flow patterns, mainly bubbly, slug, annular, and churn flow as mentioned before, and different liquid viscosities. The attempted contribution of this study is to suggest the most appropriate correlations depending on the operating conditions mentioned previously. Additionally, this study intends to determine which pipe inclinations and flow patterns should require further research on the development of empirical correlations based on statistical analysis.

The article is structured as follows: firstly, a brief definition of the different types of correlations used in the study, continued by the description of the methodology in which the database is summarized and analyzed. Additionally, a statistical analysis section is added to explain the indicators used and to determine the ones that were given more importance in this study. After that, all the results, divided by flow pattern and viscosity intervals, are shown and analyzed for each pipe inclination. Finally, the most remarkable conclusions obtained through this study are listed.

\subsection{Correlations}

The void fraction parameter, $\varepsilon$, which is the volume of space occupied by the gas in the flow, is the most fundamental parameter in the study of gas-liquid flow since it allows different flow calculations, such as the two-phase mixture density, viscosity and pressure drop. Therefore, many experimental studies have been made in order to 
determine the value of the void fraction in a two-phase flow. For that reason, several correlations have been established to predict the behavior of the void fraction [4].

In general, the correlations used in this study have been classified in four different categories: slip ratio, $K \varepsilon_{H}$, drift flux, and general correlations, according to the work of Vijayan et al. [7]. The categories and the equations of each correlation studied are depicted in Annex A.

Slip ratio correlations are based on the slip ratio, which is the velocity of the liquid particle, $u_{s L}$, divided by the velocity of the conveying gas, $u_{s G}$. This correlation assumes that the two phases travel at two different velocities, but if a homogeneous flow is considered, the ratio would be equal to one, $u_{s L}=u_{s G}$ [8]. The general expression (see Annex A), depends on three different ratios between the densities and the viscosities of the gas and liquid, and between the wetness fraction and the quality [1].

$K \varepsilon_{H}$ correlations are calculated by multiplying a constant or factor by the homogeneous void fraction $\varepsilon_{H}$. Consequently, the slip ratio is considered equal to one, and this type of correlation is considered as a homogeneous model [7].

Correlations based on the drift flux model are numerous since they were developed in order to predict the void fraction considering the non-uniformity in the flow and the void distribution in the medium. This type of correlation includes the drift velocity, $u_{s G m}$, explained as the difference between the gas velocity $u_{s G}$ and the phase mixture velocity $u_{m}$, and a distribution coefficient $C_{0}$ [1]. For homogeneous flow, $C_{0}$ and $u_{s G m}$ would be equal to 1 and 0 , respectively [7].

Finally, the general correlations are mostly empirical and based on dimensionless numbers that consider physical principles, such as the Froude, Weber, and Reynolds numbers.

\section{Methodology}

\subsection{Data handling}

A database consisting of 11,895 data points was compiled considering Amaya et al.'s study [9] to validate the results of the analyzed empirical correlations. The data set used is summarized in Table 1. It was separated into the flow pattern and the pipe inclination, in order to perform an extensive analysis of these variables based on the accuracy of the empirical correlations. Additionally, other data collection was classified in terms of liquid viscosity, as the cases analyzed had liquid viscosities varying from 0 to $10 \mathrm{cP}$ and above. Given this, the viscosity also became a variable of influence on the accuracy of the empirical correlations. Figure 1 presents a summary of the data collection according to flow pattern, pipe orientation, and liquid viscosity intervals.

\subsection{Statistical analysis}

Most of the correlations considered only apply for a limited range of operational conditions. Therefore, when these correlations are evaluated for a broader set of cases, it is very likely to observe significant deviations that do not necessarily reflect on the validity of the model. Additionally, it is essential to consider that void fraction values are between 0 and 1 , which means that the magnitudes are low, compared to pressure drop values. For this reason, many statistical indicators for these values have been defined to evaluate the adjustment of the correlations to the experimental data. In this context, Shoham [68], and Ansari et al. [69] have defined some statistical indicators presented in Eqs. (1)-(10) to evaluate the results obtained [3].

$e_{R}=\frac{\varepsilon_{C}-\varepsilon_{M}}{\varepsilon_{M}}$

$E_{1}=\frac{1}{n}\left(\sum_{i=1}^{n} e_{R, i}\right) \times 100$

$E_{2}=\frac{1}{n}\left(\sum_{i=1}^{n}\left|e_{R, i}\right|\right) \times 100$

$E_{3}=\sum_{i=1}^{n} \sqrt{\frac{\left(e_{R, i} \times 100-E_{1}\right)^{2}}{n-1}}$

$e_{A}=\varepsilon_{C}-\varepsilon_{M}$

$E_{4}=\frac{1}{n}\left(\sum_{i=1}^{n} e_{A, i}\right)$

$E_{5}=\frac{1}{n}\left(\sum_{i=1}^{n}\left|e_{A, i}\right|\right)$

$E_{6}=\left(\sum_{i=1}^{n} \sqrt{\frac{\left(e_{A, i}-E_{4}\right)^{2}}{n-1}}\right)$

$F_{R P}=\left(\sum_{i=1}^{6} \frac{\left|E_{i}\right|-\left|E_{i, \text { min }}\right|}{\left|E_{i, \text { max }}\right|-\left|E_{i, \text { min }}\right|}\right)$ 
Table 1 Summary of the experimental data used in this study

\begin{tabular}{|c|c|c|c|c|c|c|c|}
\hline Author & Fluids & Diameter (cm) & L/D & $V_{s g}(m / s)$ & $V_{l g}(m / s)$ & $\Theta$ & $\begin{array}{l}\text { Number of } \\
\text { data points }\end{array}$ \\
\hline Abdulkadir [10] & Silicone oil-air & 6.70 & 89.55 & $0.047-4.727$ & $0.047-0.378$ & $90^{\circ}$ & 78 \\
\hline Adedigba [11] & Water-air & 5.00 & 120.00 & $0.030-2.590$ & $0.150-3.000$ & $0^{\circ}$ & 51 \\
\hline Aggour [12] & $\begin{array}{l}\text { Water-air, freon, } \\
\text { helium }\end{array}$ & 1.17 & 13.04 & $0.073-96.027$ & $0.314-10.580$ & $90^{\circ}$ & 206 \\
\hline $\begin{array}{l}\text { Agrawal et al. } \\
\text { [13] }\end{array}$ & Oil-air & 3.04 & 1011.83 & $0.109-6.066$ & $0.014-0.061$ & $0^{\circ}$ & 45 \\
\hline Alamu [14] & Water-air & 1.90 & 368.42 & $13.130-42.901$ & $0.030-0.194$ & $90^{\circ}$ & 37 \\
\hline Al-Lababidi [15] & Water-air & 5.00 & 440.00 & $0.600-3.150$ & $0.300-1.030$ & $0^{\circ}$ & 33 \\
\hline Almabrok [16] & Water-air & 10.16 & 59.06 & $0.206-34.263$ & $0.070-1.500$ & $\pm 90^{\circ}$ & 270 \\
\hline Alsaadi [17] & Water-air & 7.62 & 232.28 & $1.829-39.992$ & $0.010-0.101$ & $\begin{array}{l}2^{\circ}, 5^{\circ}, 10^{\circ}, 20^{\circ} \\
\text { and } 30^{\circ}\end{array}$ & 288 \\
\hline Alssayh [18] & Water-air & 5.00 & 440.00 & $0.600-7.500$ & $0.300-1.030$ & $0^{\circ}$ & 60 \\
\hline Andritsos [19] & $\begin{array}{l}\text { Water + glycerin- } \\
\text { air }\end{array}$ & 2.51 and 9.53 & $\begin{array}{l}104.987,258.268 \\
397.678 \text { and } \\
616.400\end{array}$ & 0.799-98.880 & $0.000-0.335$ & $0^{\circ}$ & 513 \\
\hline Asante [20] & Oil, water-air & $\begin{array}{l}2.54,5.08 \text { and } \\
7.62\end{array}$ & $\begin{array}{c}498.69,748.03 \\
\text { and } 1496.06\end{array}$ & $15.000-30.000$ & $0.000-0.200$ & $0^{\circ}$ & 473 \\
\hline $\begin{array}{l}\text { Govier and Aziz } \\
\text { [21] }\end{array}$ & Oil-air & 3.04 & 515.12 & $0.015-3.688$ & $0.030-1.648$ & $0^{\circ}$ & 179 \\
\hline Brito [22] & Oil-air & 5.08 & 374.02 & $0.094-7.738$ & $0.010-2.961$ & $0^{\circ}$ & 340 \\
\hline Caetano [23] & $\begin{array}{l}\text { Kerosene, water- } \\
\text { air }\end{array}$ & 6.34 & 252.37 & $0.020-22.860$ & $0.010-3.580$ & $90^{\circ}$ & 478 \\
\hline Chung et al. [24] & $\begin{array}{l}\text { Lubsoil ND-50- } \\
\text { air }\end{array}$ & 5.08 & 447.24 & $0.618-7.837$ & $0.048-0.704$ & $-90^{\circ}$ & 131 \\
\hline Chupin [25] & Oil, water-air & 6.00 and 6.04 & 33.33 and 99.34 & $4.930-29.600$ & $0.000-0.040$ & $0^{\circ}, 0.5^{\circ}$ and $1^{\circ}$ & 93 \\
\hline Ekinci [26] & Oil-natural gas & 5.08 & 372.05 & $0.088-5.145$ & $0.095-0.817$ & $-2^{\circ}$ and $2^{\circ}$ & 910 \\
\hline Faccini et al. [27] & Water-air & 2.52 & 309.52 & $0.245-2.673$ & $0.111-0.557$ & $-2.5^{\circ}$ and $-10^{\circ}$ & 17 \\
\hline Fan [28] & Water-air & 5.08 and 14.96 & $\begin{array}{c}334.65 \text { and } \\
377.01\end{array}$ & $4.929-25.701$ & $0.000-0.052$ & $\pm 2^{\circ}, \pm 1^{\circ}$ and $0^{\circ}$ & 351 \\
\hline Fernandez [29] & Oil-air & 5.08 and 7.62 & $\begin{array}{c}240.03 \text { and } \\
360.04\end{array}$ & $4.950-17.890$ & $0.016-0.046$ & $90^{\circ}$ & 35 \\
\hline $\begin{array}{l}\text { França and Lahey } \\
\text { [30] }\end{array}$ & Water-air & 1.90 & 96.32 & $0.130-23.760$ & $0.010-14.850$ & $0^{\circ}$ & 99 \\
\hline $\begin{array}{l}\text { Ghajar and Tang } \\
\text { [31] }\end{array}$ & Water-air & 1.27 and 2.79 & $\begin{array}{c}100.14 \text { and } \\
123.94\end{array}$ & $0.190-26.724$ & $0.024-1.170$ & $\begin{array}{l}0^{\circ}, 2^{\circ}, 5^{\circ}, 7^{\circ} \text { and } \\
90^{\circ}\end{array}$ & 925 \\
\hline Gokcal [32] & Oil-air & 5.04 & 375.00 & $0.090-20.300$ & $0.010-1.760$ & $0^{\circ}$ & 183 \\
\hline $\begin{array}{l}\text { Govier and Leigh } \\
\text { [33] }\end{array}$ & Water-air & 3.08 & 366.47 & $0.044-27.392$ & $0.003-2.204$ & $0^{\circ}$ and $90^{\circ}$ & 194 \\
\hline $\begin{array}{l}\text { Gregory et al. } \\
\text { [34] }\end{array}$ & Oil-air & 2.48 and 5.12 & $\begin{array}{l}340.00 \text { and } \\
575.00\end{array}$ & $0.046-15.626$ & $0.030-2.316$ & $0^{\circ}$ & 154 \\
\hline $\begin{array}{l}\text { Griffith and Wallis } \\
\text { [35] }\end{array}$ & Oil-natural gas & 5.70 & $10,694.74$ & $0.052-0.810$ & $0.109-1.368$ & $\begin{array}{l}30^{\circ}, 50^{\circ}, 60^{\circ}, 70^{\circ} \\
\text { and } 90^{\circ}\end{array}$ & 351 \\
\hline Güler-Quadir [36] & Water-air & 8.89 & 8098.99 & $0.119-17.749$ & $0.037-1.667$ & $\begin{array}{l}90^{\circ} \\
90^{\circ}\end{array}$ & 102 \\
\hline Haoulo [37] & Water-air & 3.81 & 65.35 & $2.958-37.739$ & $0.019-1.867$ & $0^{\circ}$ and $1^{\circ}$ & 349 \\
\hline Jeyachandra [38] & Oil-air & 5.08 & 372.05 & $0.100-3.600$ & $0.100-0.800$ & $2^{\circ}$ & 123 \\
\hline Karami [39] & Water-air & 15.24 & 370.08 & $7.400-22.600$ & $0.010-0.027$ & $0^{\circ}$ & 106 \\
\hline Kim et al. [40] & Water-air & 2.54 & 96.06 & $0.130-1.676$ & $0.034-0.511$ & $0^{\circ}$ & 26 \\
\hline Kokal [41] & Light oil-air & $\begin{array}{l}2.58,5.12 \text { and } \\
7.63\end{array}$ & $\begin{array}{c}313.37,463.87 \\
\text { and } 931.01\end{array}$ & $0.030-19.421$ & $0.030-3.048$ & $\begin{array}{l} \pm 9^{\circ}, \pm 5^{\circ}, \pm 1^{\circ} \\
\text { and } 0^{\circ}\end{array}$ & 871 \\
\hline Kouba [42] & Kerosene-air & 7.62 & 418.00 & $0.302-7.361$ & $0.152-2.137$ & $0^{\circ}$ & 53 \\
\hline $\begin{array}{l}\text { Liu and Wang } \\
\text { [43] }\end{array}$ & Water-air & 0.24 and 0.30 & $\begin{array}{l}274.34 \text { and } \\
386.92\end{array}$ & $0.001-4.276$ & $0.002-1.499$ & $90^{\circ}$ & 273 \\
\hline
\end{tabular}


Table 1 (continued)

\begin{tabular}{|c|c|c|c|c|c|c|c|}
\hline Author & Fluids & Diameter (cm) & L/D & $\mathrm{V}_{\mathrm{sg}}(\mathrm{m} / \mathrm{s})$ & $V_{\mathrm{lg}}(\mathrm{m} / \mathrm{s})$ & $\Theta$ & $\begin{array}{l}\text { Number of } \\
\text { data points }\end{array}$ \\
\hline Lunde [44] & $\begin{array}{l}\text { Naphtha-nitro- } \\
\text { gen }\end{array}$ & 29.00 & 320.69 & $0.500-1.000$ & $0.500-2.000$ & $5^{\circ}$ & 4 \\
\hline Mantilla [45] & $\begin{array}{l}\text { Water, } \\
\qquad \begin{array}{l}\mathrm{H}_{2} \mathrm{O}+\text { butanol } \\
5 \%, \mathrm{H}_{2} \mathrm{O}+\text { glyc- } \\
\text { erin } 47 \% \text { - air }\end{array}\end{array}$ & 5.08 and 15.24 & 53.00 and 253.00 & $1.500-82.200$ & $0.003-0.100$ & $0^{\circ}$ & 143 \\
\hline Mata [46] & Water-air & 1.04 & 240.38 & $0.164-14.715$ & $0.164-0.818$ & $90^{\circ}$ & 30 \\
\hline Meng [47] & Oil-air & 5.01 & 377.25 & $4.800-26.400$ & $0.001-0.054$ & $0^{\circ}$ & 194 \\
\hline $\begin{array}{l}\text { Mora and Zegrí } \\
\text { [48] }\end{array}$ & Water-air & 2.10 & 228.57 & $0.218-10.628$ & $0.048-1.623$ & $0^{\circ}$ & 39 \\
\hline Mukherjee [49] & $\begin{array}{l}\text { Kerosene, lube } \\
\text { oil-air }\end{array}$ & $\begin{array}{l}3.81,5.08 \text { and } \\
10.16\end{array}$ & $\begin{array}{l}129.17,192.00 \\
240.00 \text { and } \\
256.00\end{array}$ & $0.043-36.262$ & $0.009-4.363$ & $\begin{array}{l}0, \pm 1,5, \pm 20,30 \\
45,50, \pm 70,80 \\
\text { and } 90^{\circ}\end{array}$ & 595 \\
\hline $\begin{array}{l}\text { Nicholson et al. } \\
\text { [50] }\end{array}$ & Oil-natural gas & 3.05 & $13,320.21$ & $0.070-28.497$ & $0.030-2.998$ & $\pm 1^{\circ}, \pm 5^{\circ}$ and $\pm 9^{\circ}$ & 489 \\
\hline Nuland [51] & $\begin{array}{l}\text { Light oil (Exxsol } \\
\text { D80)-SF6 }\end{array}$ & 6.00 & 250.00 & $0.990-3.050$ & $0.099-1.1017$ & $\begin{array}{l}10^{\circ}, 20^{\circ}, 45^{\circ} \text { and } \\
60^{\circ}\end{array}$ & 20 \\
\hline $\begin{array}{l}\text { Nydal and } \\
\text { Andreussi [52] }\end{array}$ & Water, oil-air & $\begin{array}{l}3.10,5.30 \text { and } \\
9.00\end{array}$ & $\begin{array}{c}144.44,245.28 \\
\text { and } 419.35\end{array}$ & $0.226-24.590$ & $0.590-3.500$ & $0^{\circ}$ & 173 \\
\hline Rosa et al. [53] & Water-air & 2.60 & 257.69 & $0.120-28.800$ & $0.220-3.080$ & $90^{\circ}$ & 73 \\
\hline $\begin{array}{l}\text { Schubring et al. } \\
\text { [54] }\end{array}$ & Water-air & 2.37 & 150.00 & $35.600-83.500$ & $0.063-0.338$ & $90^{\circ}$ & 25 \\
\hline Shanmugam [55] & Water-air & 2.61 & 229.56 & $4.396-17.582$ & $0.235-0.470$ & $90^{\circ}$ & 12 \\
\hline Skopich [56] & Water-air & 5.08 and 10.166 & $\begin{array}{l}150.00 \text { and } \\
300.00\end{array}$ & $7.986-29.490$ & $0.009-0.050$ & $90^{\circ}$ & 35 \\
\hline Smith [57] & Water-air & 5.08 & 24.02 & $8.433-24.753$ & $0.000-0.001$ & $2^{\circ}$ & 209 \\
\hline Sujumnong [58] & Water-air & 1.17 & 130.14 & $0.053-98.669$ & $0.035-81.424$ & $90^{\circ}$ & 171 \\
\hline Tang et al. [59] & Water-air & 1.86 & 245.70 & $0.033-39.851$ & $0.009-1.396$ & $0^{\circ}$ & 296 \\
\hline Vieira et al. [60] & $\begin{array}{c}\text { Water + CMC, } \\
\text { water-air }\end{array}$ & 7.60 & 236.84 & $9.000-40.000$ & $0.005-0.200$ & $0^{\circ}$ and $90^{\circ}$ & 127 \\
\hline Vijay [61] & $\begin{array}{l}\text { Water, glycerol- } \\
\text { air }\end{array}$ & 1.17 & 130.43 & $0.050-96.772$ & $0.012-10.607$ & $90^{\circ}$ & 333 \\
\hline $\begin{array}{l}\text { Vongvuthiporn- } \\
\text { chai [62] }\end{array}$ & Kerosene-air & 7.62 & 5600.00 & $0.060-2.940$ & $0.070-2.030$ & $0^{\circ}$ & 42 \\
\hline $\begin{array}{l}\text { Wang and Ching } \\
\text { [63] }\end{array}$ & Water-air & 7.62 & 853.02 & $0.150-0.400$ & $1.050-2.040$ & $90^{\circ}$ & 3 \\
\hline Xu and Wu [64] & Water, CMC-air & 2.00 and 4.00 & $\begin{array}{l}250.00 \text { and } \\
500.00\end{array}$ & $0.011-13.420$ & $0.488-2.085$ & $-15^{\circ}, 0^{\circ}$ and $15^{\circ}$ & 297 \\
\hline Yuan [65] & Water-air & 7.62 & 229.66 & $9.900-36.000$ & $0.0100-0.100$ & $\begin{array}{l}30^{\circ}, 60^{\circ}, 75^{\circ} \text { and } \\
90^{\circ}\end{array}$ & 146 \\
\hline Zhao et al. [66] & Water-air & 5.00 & 201.68 & $0.380-1.500$ & $0.016-0.610$ & $90^{\circ}$ & 21 \\
\hline Zhu [67] & Water-air & 20.00 & 47.80 & $0.020-0.240$ & $0.250-0.450$ & $90^{\circ}$ & 21 \\
\hline
\end{tabular}

$R^{2}=\frac{\left(\sum \varepsilon_{C} \varepsilon_{M}-\frac{1}{n} \sum \varepsilon_{C} \varepsilon_{M}\right)^{2}}{\left(\sum \varepsilon_{M}^{2}-\frac{1}{n}\left(\sum \varepsilon_{M}\right)^{2}\right)\left(\sum \varepsilon_{C}^{2}-\frac{1}{n}\left(\sum \varepsilon_{C}\right)^{2}\right)}$

The actual error (eA) is the difference between the calculated void fraction and the measured one, while the relative error $(e \mathrm{R})$ is the actual error divided by the measured value. Hence, the relative error indicates how accurate a measurement is relative to the magnitude of the item being measured, allowing a better understanding of the analyzed variables [70]. Moreover, the average percent error, $E_{1}$, is a measure of the difference between the predicted and the measured data, to indicate the over- or under-prediction if the error is positive or negative, respectively. The absolute average percent error, $E_{2}$, is a more meaningful indicator than $E_{1}$, because absolute parameters allow for positive and negative errors to not 
Fig. 1 Data collection according to flow pattern and viscosity for: a, d horizontal, b, e vertical and $\mathbf{c}$, $\mathbf{f}$ inclined pipes. Viscosity in $[\mathrm{CP}]$ (a) Horizontal Pipe - Datapoints: 4430

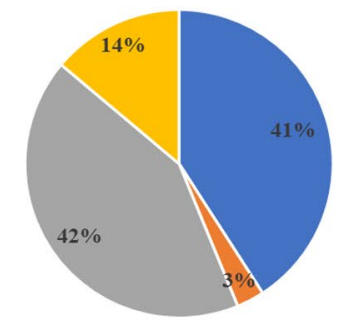

- Slug = Bubbly $=$ Churn $=$ Annular (b) Vertical Pipe - Datapoints: 2781

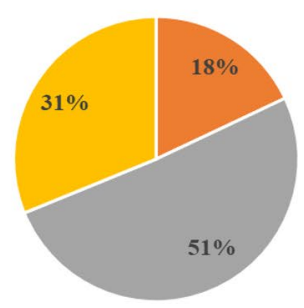

- Slug | Bubbly $\mid$ Churn | Annular

(c) Inclined Pipe - Datapoints: 4684

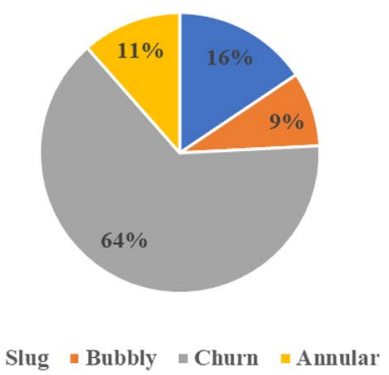

(d) Horizontal Pipe - Datapoints: 4430

(e) Vertical Pipe - Datapoints: 2781
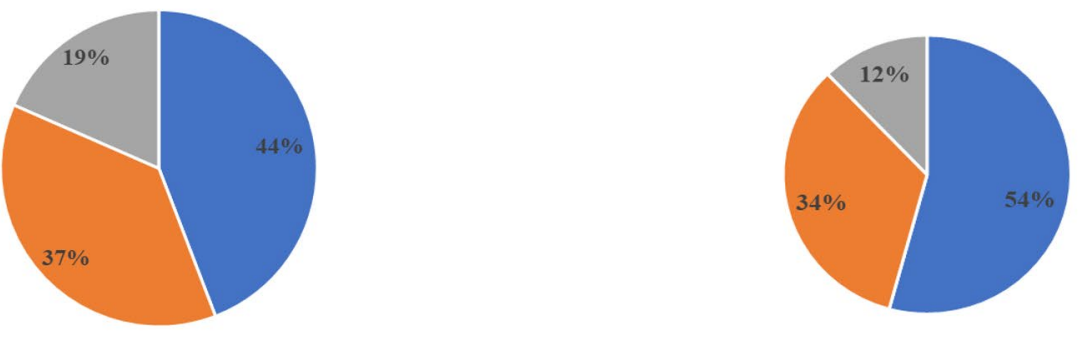

- $\mu \leq 1 \quad\|1<\mu \leq 10 \quad\| \mu>10$

(f) Inclined Pipe - Datapoints: 4684

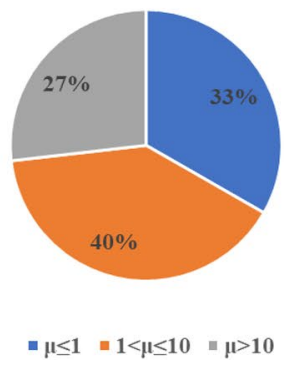

cancel each other out, thus, $E_{2}$ indicates how large the errors are on average [69]. The percent standard deviation, $E_{3}$, indicates the degree of scattering of the errors about their average value [69]. On the other hand, the average error, $\mathrm{E}_{4}$, measures the global trend of the values independent of the measured data. In the same way, $\mathrm{E}_{5}$, the absolute average error, indicates the magnitude of the average error, while the standard deviation, $\mathrm{E}_{6}$, is a measure of the scattering of the results.

\section{SN Applied Sciences}


From the definitions described, it can be stated that the first three parameters, $E_{1}, E_{2}$, and $E_{3}$, which are based on the relative error, are more suitable for the evaluation of small values in comparison to the other three $\left(E_{4}, E_{5}\right.$, and $E_{6}$ ), which are appropriate for larger values [68]. In consequence, due to the values of the void fraction in this study, which are in an interval of 0.00093 to 1 , it is more appropriate to use the first three parameters. This can be corroborated by observing that, in the literature, the most significant statistical parameters that have been used to evaluate void fraction correlations are precisely the $E_{1}, E_{2}$ and $\mathrm{E}_{3}$ [71].

As a way of making a comparison among correlations and models, it is required to use a relative performance factor $\left(F_{\mathrm{RP}}\right)$, as introduced by Ansari et al. [69]. The minimum and maximum possible values for this statistical parameter are 0 and 6 , indicating the best and worst adjustment, respectively [69]. This parameter is also relevant because a value near to 6 indicates that most of the error and deviations $\left(E_{i}\right)$ are similar to the maximum value $\left(E_{i, \text { max }}\right)$, giving an inaccurate prediction. Finally, the determination coefficient is a measure of how well the calculated data represents the measured values. In consequence, if this value is closer to one, it represents a more significant variation of the response variable.

\section{Results and discussion}

The main results of this study will be separated into two sections. The first one will cover the results obtained by pipe inclination and flow pattern, while the second section will present the results categorized by liquid viscosity interval and pipe inclination, as stated before in Sect. 2.1.

\subsection{Results of correlations by the flow pattern}

From the 63 different correlations evaluated, the five correlations that gave the lowest absolute error $\left(E_{2}\right)$ were selected for each flow pattern, and they are presented with their respective statistical results in order to avoid unnecessary analysis on models with low predictive capabilities. A higher importance was given to the absolute average error because the positive and negative errors do not cancel each other, giving the best prediction of the deviation of the experimental and calculated data; nevertheless, $E_{1}, R^{2}$, and the total percentage of the data points that were correctly predicted within the specified index were also analyzed depending on each case. Table 2 summarizes the main results obtained for horizontal, vertical, and inclined pipes on the slug, annular, bubbly, and churn flow patterns.

\subsubsection{Results on horizontal pipes}

Figure 2 presents the graphical results of the deviation from the best performing correlations per-flow pattern, namely: Hart et al. [72], Chen [77], Kokal and Stanislav [79], and Bestion [84] for slug, annular, bubbly, and churn flow patterns, respectively.

In Fig. 2, it is shown that the slug-flow correlation developed by Hart et al. [72] tends to make a better prediction in comparison to the other flow patterns, predicting $84 \%$ of the measured data within an error of $\pm 10 \%$. Moreover, from the statistical analysis, $E_{2}$ values were significantly lower for this flow pattern in spite of the slight overprediction observed.

Nevertheless, it was necessary to analyze the upper left points shown in Fig. 2a. These points of high deviation could be explained by certain experimental errors of the measured data, for example, a vapor quality measurement error. It is also essential to take into account the assumptions and the operational conditions of Hart et al.'s [72] correlation. In this study, the authors stated that this correlation predicts liquid-holdup between 0 and 0.06 , within a $10 \%$ error, that means, a void fraction between 0.94 and 1.0. Therefore, considering that $83 \%$ of our database relies on a range of void fraction between 0.8 and 1.0 (as seen in Fig. 3), it is expected that this correlation accurately predicts almost all of the experimental data. Consequently, this correlation is not recommended to predict void fractions below that range (Fig. 2a), which is consistent with the characteristics of slug flow because this pattern only occurs when the void fraction increases enough to produce large bubbles with liquid sections in-between.

In the case of the annular flow pattern, Chen's [77] correlation predicted $82 \%$ of the measured data within an error of $\pm 10 \%$, which means that almost 101 data points were not predicted within this range of error. Analyzing the correlation, the author affirms that there are two areas where the correlation is not accurate, one is the case when the system is at $4700 \mathrm{kN} / \mathrm{m}^{2}$, and the other is the case where it is at atmospheric pressure and quality higher than 0.1. Thus, considering that the highest pressure in our database is $1000 \mathrm{kN} / \mathrm{m}^{2}$, the first case does not apply for this study, unlike the second case, where almost 13\%, 82 data points, of the horizontal annular-flow pattern data relies upon the second scenario. Therefore, it can be settled that this study verifies the conclusions obtained by Chen [77], as the correlation has shown to be accurate for a wide range of conditions, except for the second scenario exposed before.

For the bubbly flow pattern, the absolute errors were more significant in comparison to the patterns analyzed previously, and most of the values correspond to underpredictions (negative average percent errors). The best five 
Table 2 Results on the statistical analysis per-flow pattern on horizontal, vertical and inclined pipes

\begin{tabular}{|c|c|c|c|c|c|}
\hline Correlation & $E_{1}(\%)$ & $E_{2}(\%)$ & $E_{3}(\%)$ & $F_{R P}$ & $R^{2}$ \\
\hline \multicolumn{6}{|l|}{ Horizontal pipes } \\
\hline & \multicolumn{5}{|l|}{ Slug } \\
\hline Hart et al. [72] & 1.87 & 13.75 & 630.94 & $1.26 e^{-5}$ & 0.68 \\
\hline Dix [73] & 5.43 & 14.15 & 762.74 & $1.83 e^{-5}$ & 0.63 \\
\hline Woldesemayat and Ghajar [1] & 8.38 & 14.33 & 843.16 & $2.04 e^{-5}$ & 0.61 \\
\hline Minami and Brill [74] & 14.02 & 15.74 & 942.96 & $3.50 e^{-5}$ & 0.60 \\
\hline \multirow[t]{2}{*}{ Baroczy [75] } & 13.19 & 15.85 & 969.39 & $3.36 e^{-5}$ & 0.55 \\
\hline & \multicolumn{5}{|l|}{ Annular } \\
\hline Chen [77] & 31.51 & 34.67 & 1475.80 & $1.77 e^{-11}$ & 0.13 \\
\hline Baroczy [75] & 29.45 & 34.70 & 1462.16 & $1.68 e^{-11}$ & 0.14 \\
\hline Lockhart and Martinelli [76] & 28.61 & 34.74 & 1447.21 & $1.65 e^{-11}$ & 0.13 \\
\hline Woldesemayat and Ghajar [1] & 30.05 & 34.81 & 1462.73 & $1.72 e^{-11}$ & 0.12 \\
\hline \multirow[t]{2}{*}{ Chisholm [78] } & 31.01 & 34.88 & 1475.56 & $1.76 e^{-11}$ & 0.11 \\
\hline & \multicolumn{5}{|l|}{ Bubbly } \\
\hline Kokal and Stanislav [79] & -15.42 & 42.01 & 414.12 & $2.54 e^{-17}$ & 0.83 \\
\hline Bonnecaze et al. [80] & -15.56 & 42.03 & 413.51 & $2.55 e^{-17}$ & 0.83 \\
\hline Nicklin et al. [81] & -15.59 & 42.03 & 413.39 & $2.55 e^{-17}$ & 0.83 \\
\hline Zuber and Findlay [82] & -13.89 & 42.14 & 422.46 & $2.44 e^{-17}$ & 0.83 \\
\hline \multirow[t]{2}{*}{ Guzhov et al. [83] } & -9.84 & 42.38 & 444.77 & $2.16 e^{-17}$ & 0.83 \\
\hline & \multicolumn{5}{|l|}{ Churn } \\
\hline Bestion [84] & 17.74 & 86.45 & 4186.50 & $9.21 e^{-11}$ & 0.42 \\
\hline Kataoka and Ishii [85] & 21.89 & 88.11 & 4395.25 & $8.59 e^{-11}$ & 0.48 \\
\hline Fauske [86] & -35.74 & 89.84 & 2804.56 & $2.15 e^{-10}$ & 0.29 \\
\hline Zhao et al. [66] & -80.35 & 90.41 & 1078.15 & $3.22 e^{-10}$ & 0.11 \\
\hline Homogeneous [87] & -79.86 & 90.46 & 1109.26 & $3.21 e^{-10}$ & 0.11 \\
\hline \multicolumn{6}{|l|}{ Vertical pipes } \\
\hline & \multicolumn{5}{|l|}{ Annular } \\
\hline Yashar et al. [88] & 15.67 & 70.76 & 2367.03 & $7.78 e^{-35}$ & 0.01 \\
\hline Dimentiev et al. [89] & -69.28 & 73.95 & 731.62 & $1.73 e^{-34}$ & 0.01 \\
\hline Petalas and Aziz [90] & 3.47 & 75.24 & 2293.74 & $8.53 e^{-35}$ & 0.04 \\
\hline Neal and Bankoff [91] & 36.04 & 86.27 & 2737.44 & $1.20 e^{-34}$ & 0.01 \\
\hline \multirow[t]{2}{*}{ Filiminov et al. [92] } & -90.34 & 94.16 & 359.19 & $2.29 e^{-34}$ & 0.001 \\
\hline & \multicolumn{5}{|l|}{ Bubbly } \\
\hline Rouhani and Axelsson [93] & 18.78 & 45.66 & 1275.04 & $1.61 e^{-38}$ & 0.59 \\
\hline Bhagwat and Ghajar [2] & 17.55 & 47.34 & 1324.03 & $1.16 e^{-38}$ & 0.61 \\
\hline Kokal and Stanislav [79] & 15.86 & 47.53 & 1308.52 & $1.04 e^{-38}$ & 0.60 \\
\hline Bonnecaze et al. [80] & 15.65 & 47.58 & 1306.95 & $1.04 e^{-38}$ & 0.60 \\
\hline \multirow[t]{2}{*}{ Nicklin et al. [81] } & 15.60 & 47.60 & 1306.67 & $1.04 e^{-38}$ & 0.60 \\
\hline & \multicolumn{5}{|l|}{ Churn } \\
\hline Kokal and Stanislav [79] & 16.15 & 37.94 & 1802.73 & $2.17 e^{-11}$ & 0.56 \\
\hline Bonnecaze et al. [80] & 16.00 & 37.94 & 1801.19 & $2.21 e^{-11}$ & 0.56 \\
\hline Nicklin et al. [81] & 15.97 & 37.95 & 1801.13 & $2.22 e^{-11}$ & 0.56 \\
\hline Guzhov et al. [83] & 18.53 & 38.54 & 1811.92 & $1.55 e^{-11}$ & 0.57 \\
\hline Bhagwat and Ghajar [2] & 18.87 & 38.82 & 1895.55 & $1.19 e^{-11}$ & 0.58 \\
\hline \multicolumn{6}{|l|}{ Inclined pipes } \\
\hline & \multicolumn{5}{|l|}{ Slug } \\
\hline Chen [77] & 0.59 & 12.23 & 330.50 & $2.39 e^{-19}$ & 0.79 \\
\hline Lockhart and Martinelli [76] & -5.99 & 13.11 & 409.41 & $1.62 e^{-18}$ & 0.80 \\
\hline Hamersma and Hart [94] & -3.29 & 13.21 & 388.39 & $1.19 e^{-18}$ & 0.78 \\
\hline
\end{tabular}


Table 2 (continued)

\begin{tabular}{|c|c|c|c|c|c|}
\hline Correlation & $E_{1}(\%)$ & $E_{2}(\%)$ & $E_{3}(\%)$ & $F_{R P}$ & $R^{2}$ \\
\hline Wallis [95] & 0.51 & 13.48 & 365.40 & $9.03 e^{-19}$ & 0.79 \\
\hline \multirow[t]{2}{*}{ Spedding and Chen [96] } & -2.47 & 13.54 & 386.20 & $1.29 e^{-18}$ & 0.75 \\
\hline & Annular & & & & \\
\hline Woldesemayat and Ghajar [1] & -0.94 & 3.23 & 67.75 & $8.41 e^{-3}$ & 0.80 \\
\hline Dix [73] & -2.09 & 3.56 & 66.31 & $1.12 e^{-2}$ & 0.83 \\
\hline Toshiba [97] & -3.35 & 3.88 & 80.14 & $1.68 e^{-2}$ & 0.80 \\
\hline Maier and Coddington [87] & -2.05 & 4.08 & 89.32 & $1.44 e^{-2}$ & 0.81 \\
\hline \multirow[t]{2}{*}{ Chen [77] } & 1.73 & 4.17 & 103.54 & $1.46 e^{-2}$ & 0.58 \\
\hline & Bubbly & & & & \\
\hline Neal and Bankoff [91] & -19.83 & 46.31 & 840.24 & $7.95 e^{-13}$ & 0.88 \\
\hline Thom [98] & -30.67 & 52.77 & 762.78 & $1.14 e^{-12}$ & 0.88 \\
\hline Maier and Coddington [87] & -1.02 & 62.74 & 1245.18 & $1.04 e^{-12}$ & 0.90 \\
\hline Zivi [99] & -44.56 & 62.78 & 723.08 & $1.68 e^{-12}$ & 0.84 \\
\hline Baroczy [75] & 31.16 & 64.49 & 1687.65 & $1.50 e^{-12}$ & 0.90 \\
\hline
\end{tabular}

models predicted an average of $45 \%$ of the data studied within an error of $\pm 30 \%$. Kokal and Stanislav's [79] correlation, the one that showed the best performance, predicted 65 data points, which represents $50 \%$ of the total data within $a \pm 30 \%$ error. This model was developed for intermittent-annular transition flow, which presents an average liquid holdup of 0.25 , i.e., a void fraction of 0.75 . When comparing the void fraction distribution of the data analyzed for the horizontal bubbly-flow pattern, it was observed that all the data located within a void fraction of 0.6-1.0 were predicted through this correlation. This data represented only $16 \%$ of the total data analyzed; therefore, for values lower than 0.75 , the correlation was not accurate, predicting correctly only $41 \%$ of the data. In addition, in Fig. $2 \mathrm{c}$ it is observed that the calculated data tend to get grouped among void fraction values from 0 to approximately 0.2 . This could be explained considering that the correlation works well within a wide range of gas velocities, for high gas velocities, which is the case of the intermittent-annular transition, and also for systems located at lower velocities, which is the case of the stratified-flow pattern. Nevertheless, this correlation does not represent a correct prediction for the bubbly-flow pattern. The reason being that it was developed for the transition between intermittent-annular flow patterns, which, even if it includes the bubbly-flow regime, represents ambiguous results because the transition within these two flow regimes occurs over a wide range of gas and liquid flow rates.

On the other hand, it can be noticed that predictions for the churn flow pattern tend to be unreliable and incoherent in comparison to the other flow patterns. To highlight this observation, a noticeably wide scattering of the void fraction data points obtained for this flow pattern can be appreciated in Fig. 2d. Bestion's [84] correlation could only predict $31 \%$ of the data with an index error of $\pm 30 \%$. Moreover, by analyzing the $\mathrm{E}_{1}$, it can be observed that the models are widely inconsistent between each other, as some showed significant underprediction, while others over-predicted the void fractions. This is not observed for the rest of the flow patterns, as all correlations usually agree on under- or over-predictions. On the other hand, it has to be pointed out that it could not be determined which type of correlations could have better performance for horizontal pipes, and it is essential to consider the operational conditions for each one.

\subsubsection{Results on vertical pipes}

For vertical pipes, the prediction of the correlations was less accurate in comparison to horizontal pipes, especially for annular flow, obtaining some significant deviations. This fact is confirmed by the average $E_{2}$ values observed for churn, bubbly, and annular flow, which are equal to $38 \%, 47 \%$, and $80 \%$, respectively. These $E_{2}$ values are significantly higher than those found in the horizontal analysis, as the lowest $E_{2}$ represents a $23 \%$ increase in deviation from the horizontal models. Table 2 shows the best five correlations per-flow pattern on vertical pipes in the middle section, while in Fig. 4, the graphical results of the deviation from the best performing correlations on annular, bubbly, and churn flow are depicted. These correlations are Yashar et al. [88], Rouhani and Axelsson [93], and Kokal and Stanislav [79], respectively.

For annular flow, an underprediction of the void fraction is observed in comparison to the results on horizontal pipes. Yashar et al.'s [88] correlation could predict only $44 \%$ of the data points within an error of $\pm 30 \%$, and this behavior can be observed in Fig. 4a. This correlation is based on a viscous-only model that considers viscous 
Fig. 2 Results of void fraction for the best correlations on a slug-Hart et al. [72], b annular-Chen [77], c bubblyKokal and Stanislav [79] and d churn flow-Bestion [84]
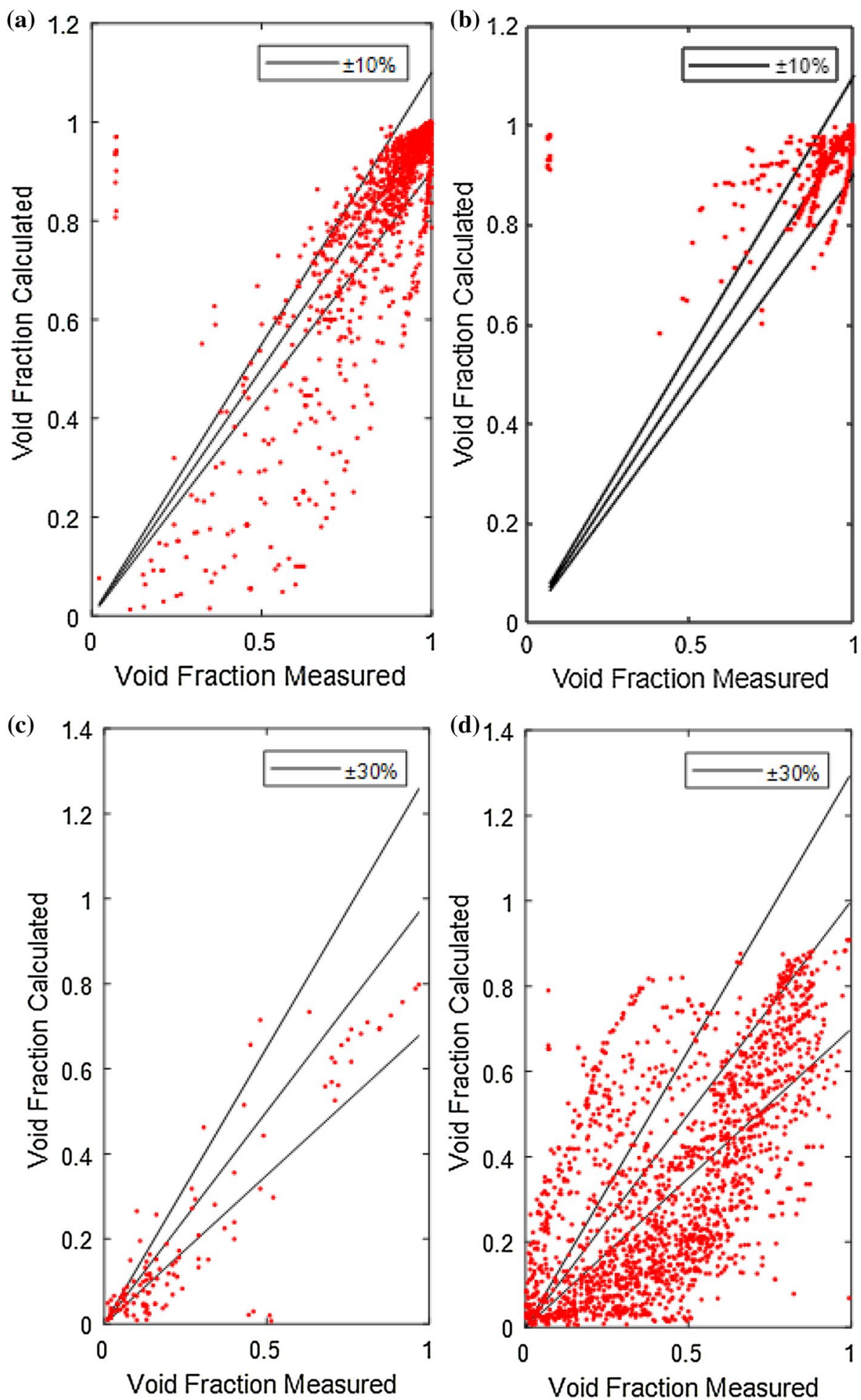

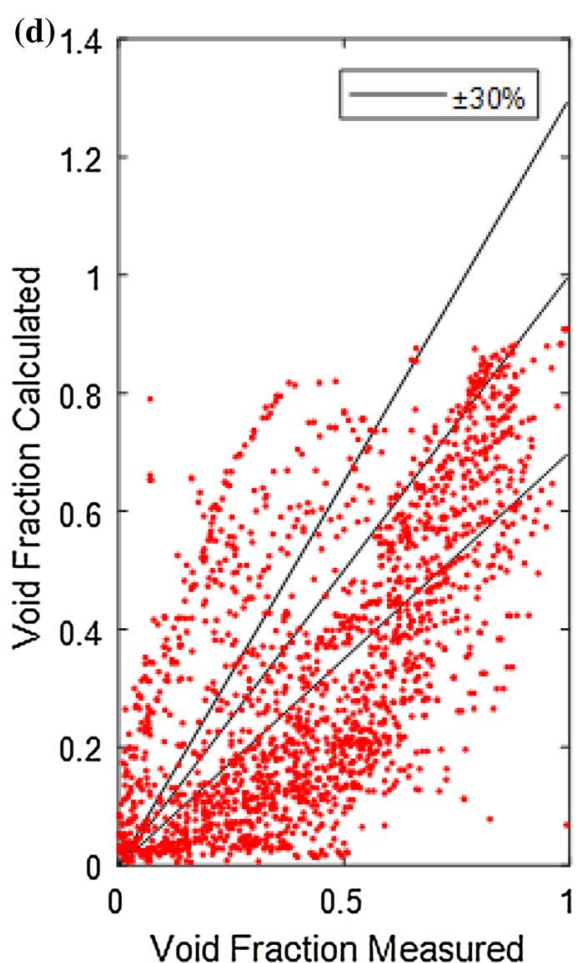

and gravitational drag effects that are characteristic of the annular flow. In the evaporation and condensation study developed by Yashar et al. [88], these two effects allowed the prediction of the void fraction over a broad range of experimental conditions for different refrigerants. They obtained an accurate prediction with their correlation for void fraction values that were in a range of approximately 0.6-0.9. Therefore, it was determined that $81 \%$ of the data points that rely on that range of $0.6-0.9$ were accurately predicted within an error $\pm 30 \%$, agreeing with the author's results. Thus, neither the values above nor below of this interval were predicted accurately, tending to one and zero, respectively, and representing $60 \%$ of the total data evaluated (Fig. 5). 


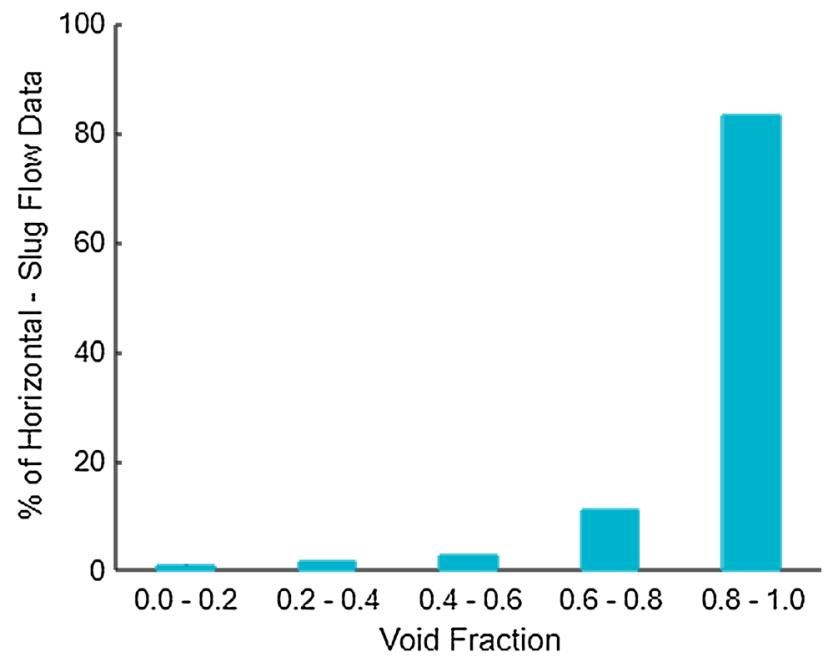

Fig. 3 Void fraction distribution data for the horizontal-slug flow pattern

For the bubbly flow pattern, Rouhani and Axelsson's [93] correlation could predict almost $75 \%$ of the data in which the gas velocity was lower than $1 \mathrm{~m} / \mathrm{s}$, and $77.2 \%$ of the data points that rely on the $0-0.2$ void fraction range. These results are consistent with the author, who affirms that this correlation has a tendency to slightly under-predict void fractions higher than 0.6 [1]. In Fig. 6 , it can be seen that very limited data points of void fractions above 0.6 were correctly predicted. Likewise, for lower values of void fraction, namely, values nearest to zero, some overprediction seems to exist, which is evident on the left side of Fig. 4b.

In the case of churn-flow, Kokal, and Stanislav [79] showed the best prediction. As was mentioned in Sect. 3.1.1., this correlation was developed initially for intermittent-annular transition, considering that intermittent refers to churn flow, and according to the authors' conclusions, this correlation is relatively not affected by the angle inclination. Therefore, $72 \%$ of the total data was predicted within an error of $\pm 20 \%$, accurately estimating $77 \%$ of the data in a void fraction interval from 0.6 to 1.0 , presenting the same behavior as in horizontal pipes with the bubbly-flow pattern. Even though the churn-flow pattern showed the lowest absolute errors for the vertical pipe cases, it is still a considerable deviation from the experimental results, which is a general behavior for all these models.

In general, bubbly and churn flow present an organized trend on the $\pm 30 \%$ and $\pm 20 \%$ region, respectively, with a slight overprediction for both patterns, compared to the results on horizontal pipes, where a high underprediction trend was detected. Furthermore, it is worth mentioning that the drift flux correlations were the bestperforming ones due to the consideration of a distribution parameter that depends on the velocity profile. According to the literature, drift flux correlations show better performance in predicting vertical pipe data, which agrees with the results obtained in this section [1]. (a)

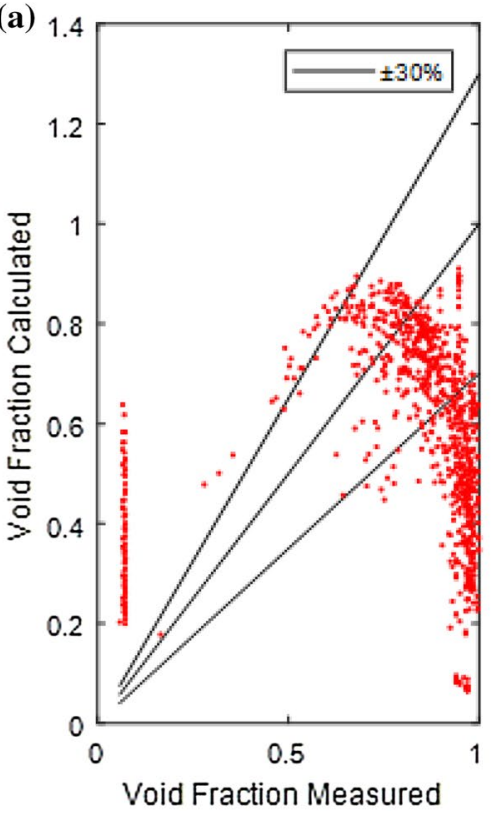

(b)

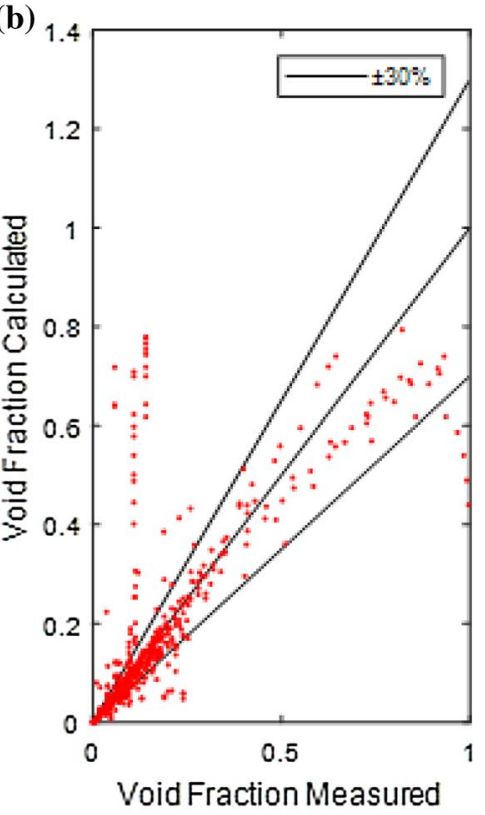

(c)

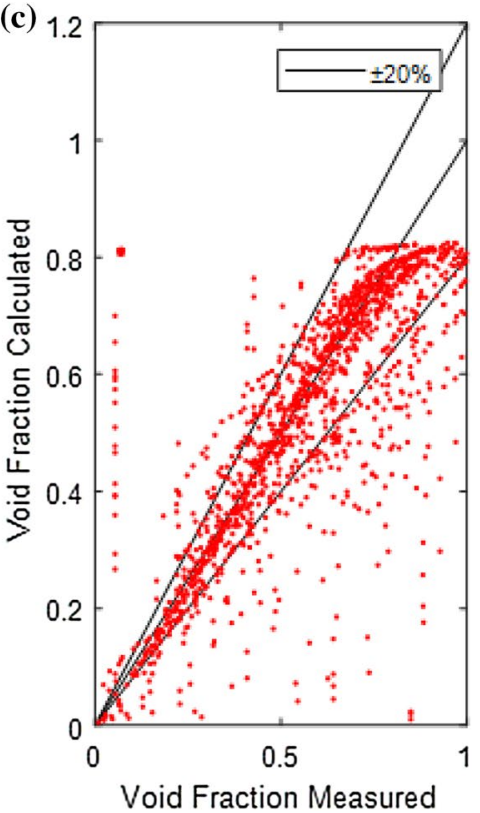

Fig. 4 Results of void fraction for the best correlations on a annular-Yashar et al. [88], b bubbly-Rouhani and Axelsson [93] and c churn flow-Kokal and Stanislav [79] 
Fig. 5 Void fraction distribution data for vertical-annular flow pattern

Fig. 6 Void fraction distribution data for vertical-bubbly flow pattern
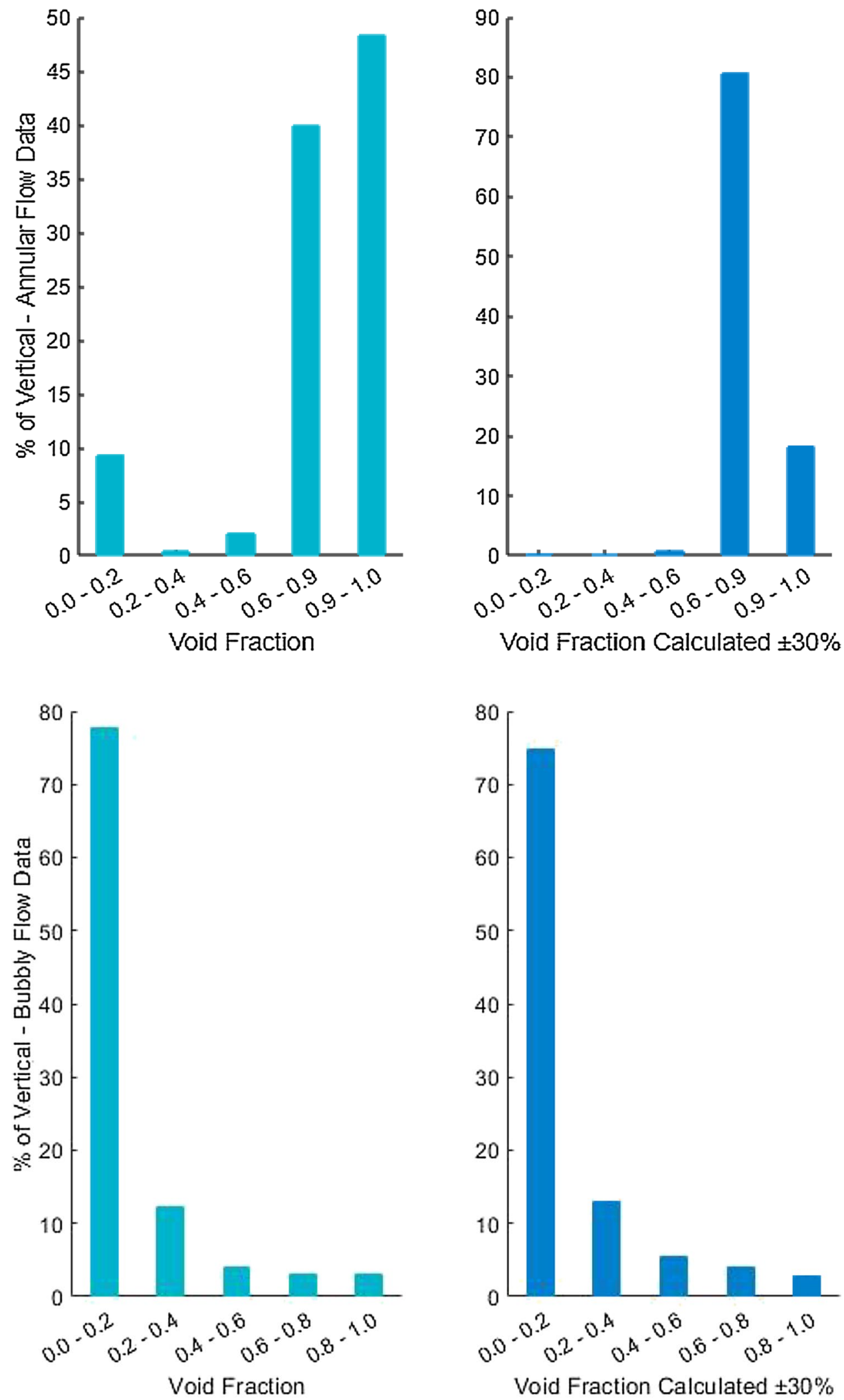

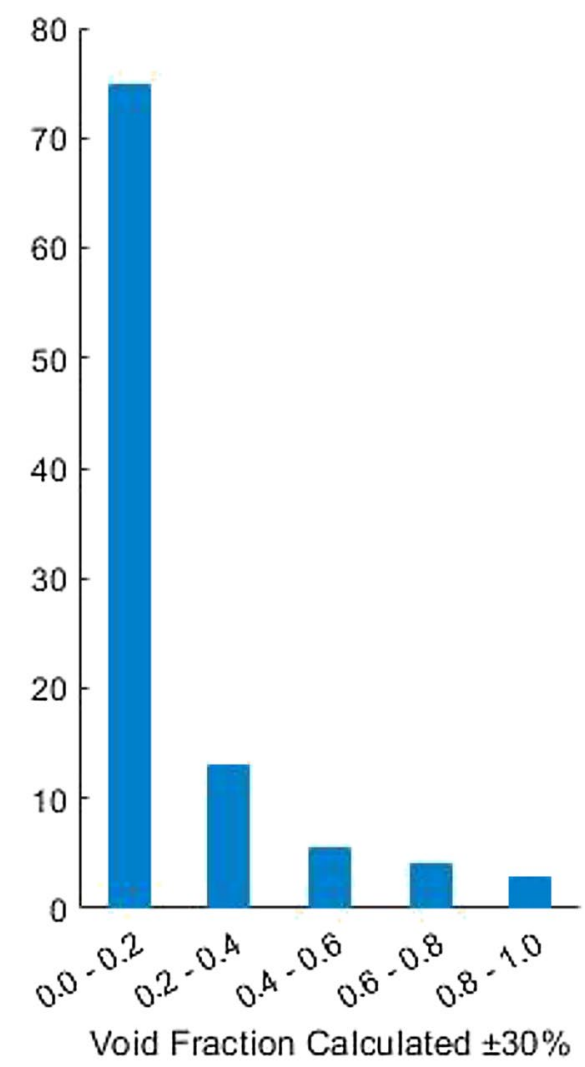




\subsubsection{Results on inclined pipes}

Regarding inclined pipes, the correlations showed high accuracy for all flow patterns, except for churn flow, where the deviations went over $100 \%$. As a consequence of these high deviations, the results for churn flow are not presented in this section. The last few rows of Table 2 show the best five correlations per-flow pattern for this pipe configuration. Additionally, the graphical results of the deviation from the best performing correlations on slug, annular, and bubbly flow are presented in Fig. 7 . These are Chen [77], Woldesemayat and Ghajar [1], and Neal and Bankoff [91], respectively.

The correlations analyzed for inclined pipes showed a better prediction of void fraction for annular flow, as $81 \%$ of the void fraction values above 0.6 were predicted accurately within $\pm 5 \%$ of index error (refer to Fig. 7b). According to the literature, Woldesemayat and Ghajar's [1] correlation, the best one found for annular flow, is an improvement of Dix's [73] correlation, which is recommended to obtain an accurate prediction for inclined pipes over a wide range of void fractions. This correlation takes into account a damping correction factor that allows a prediction within an error $\pm 5 \%$ over a wide range of system pressure, inclination angles, and diameters of the pipe, parameters that have an essential influence in inclined pipes. Hence, this accurate prediction was confirmed by obtaining an absolute error of $3 \%$ for this case.

Likewise, for horizontal pipes, the slug flow pattern was accurately estimated by Chen's [77] correlation, predicting
$77 \%$ of the void fraction data within $\pm 10 \%$ error, as evidenced in Fig. 7a. Even though this correlation was developed for annular-flow, it has shown a reasonable predicting capability for analyzing a wide range of data, including inclined pipes with either upward or downward flows. Also, this correlation can predict void fraction values in two-phase systems with pressures between 1 and 60 bar, which corresponds to the data points considered for this specific analysis. This could be confirmed by the $13 \%$ absolute error obtained. Besides, the correlation has demonstrated higher accuracy for void fractions from 0.5 to 1.0 , as shown in Fig. 8, where it can be seen that $92 \%$ of the data estimated lies within this interval, sustaining the previous hypothesis.

For bubbly flow, Neal and Bankoff's [91] correlation could predict $40 \%$ of the total data within $\pm 30 \%$ error. This correlation was developed in the study of a Mercury-Nitrogen flow, but it does not consider a damping parameter or factor for the surface tension forces, e.g., the Eötvös number. Therefore, a correlation for a Mercury system that is dominated by the capillary forces and influenced by the surface tension could not be accurate to predict other fluids or systems that are relatively unaffected by these effects.

The correlations analyzed for inclined pipes, specifically for annular flow, have a better performance in comparison to horizontal and vertical pipes. However, they exhibited inferior predictive capabilities on bubbly and churn flow. It is suggested that further research should be done on the development of reliable correlations for these particular
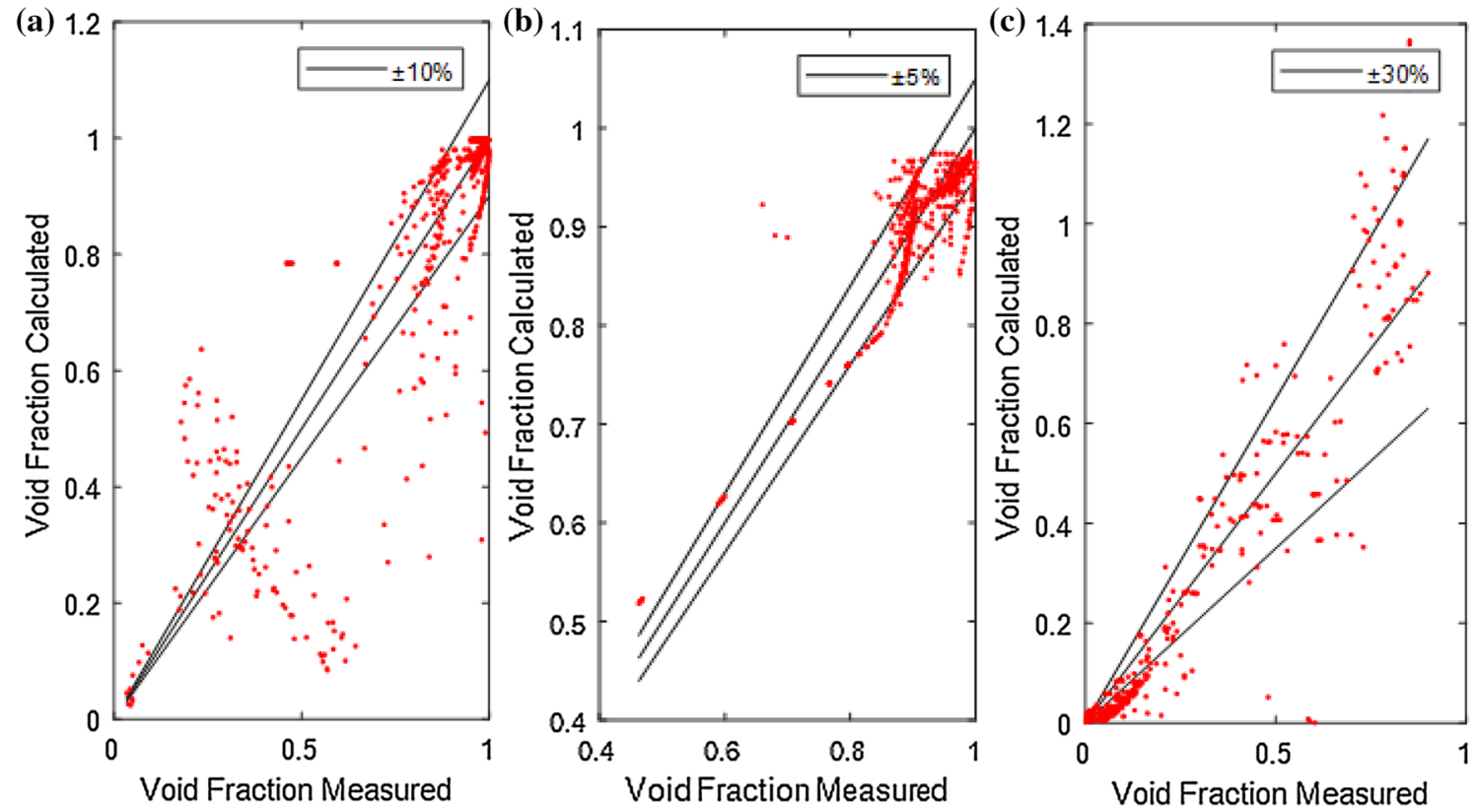

Fig. 7 Results of void fraction for the best correlations on a slug —Chen [77], b annular-Woldesemayat and Ghajar [1], and $\mathbf{c}$ bubbly flowNeal and Bankoff [91] 
Fig. 8 Void fraction distribution data for inclined pipesslug flow pattern

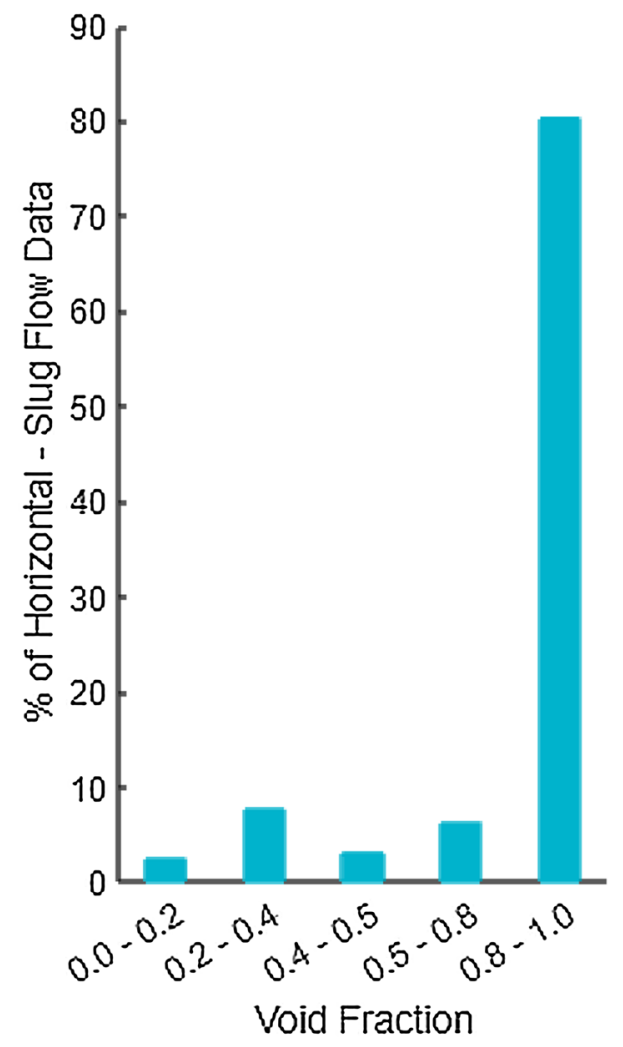

flow patterns on inclined pipelines. Also, according to the vertical cases, it is worth mentioning that the best performing correlations were drift flux correlations.

\subsection{Evaluation of correlations by viscosity intervals}

As it was mentioned before, the data analyzed also had a wide range of liquid viscosities. For this reason, and since this property plays an essential role in the dynamics of multiphase flow, a statistical analysis regarding liquid viscosity intervals was made for the different pipe inclinations. Three viscosity intervals were considered: $\mu \leq 1$, $1<\mu \leq 10$, and $\mu>10 \mathrm{CP}$. As it was performed in the previous subsection for flow patterns, from the 63 correlations considered, Table 3 shows the best 5 correlations per viscosity interval for each pipeline arrangement with their respective statistical results.

\subsubsection{Results on horizontal pipes}

In this case, the best-performing correlations were Zivi [99], homogeneous model [87], and Choi et al. [103] for the intervals $\mu \leq 1 \mathrm{cP}, 1<\mu \leq 10 \mathrm{cP}$, and $\mu>10 \mathrm{cP}$, respectively. The results for horizontal pipes show two main trends. The first one is that the correlations for these pipes have a better fit for viscosities above $10 \mathrm{cP}$, in comparison to the other two intervals, as shown in Table 3. All three significant indicators $\left(E_{1}, E_{2}\right.$, and $\left.R^{2}\right)$ are considerably lower on average for all models for the high viscosity range in comparison to the other viscosity intervals. For example, $E_{2}$ is approximately $10 \%$ and $20 \%$ lower in the $\mu>10 \mathrm{cP}$ interval than in the first and second intervals, respectively. However, the overall results show that absolute average error is higher than $30 \%$, with noticeable deviations and void fraction underpredictions, as it is shown in Fig. 9. The second trend is that the drift flux correlations are more reliable on the prediction of the void fraction for liquid viscosities above $10 \mathrm{cP}$.

In Fig. 9, a strong underprediction is noticed for all flow viscosity intervals, particularly for lower and intermediate viscosities (intervals 1 and 2). Only void fractions close to 1 , corresponding to cases with high gas presence, have an accurate prediction for all intervals. As the void fraction decreases, most of the correlations will tend to calculate values close to zero, particularly for intermediate viscosities. This is evidenced in Fig. 10, where the majority of void fractions were predicted with $\mathrm{a} \pm 20 \%$ deviation in the interval from 0.8 to 1.0 .

Moreover, in the case of the first interval, the best correlation correctly predicted $61 \%$ of the data measured with an error in the order of $\pm 20 \%$, of which $89 \%$ of the values were in the range of $0.8-1.0$. Likewise, for the second 
Table 3 Results of the statistical analysis per viscosity interval on horizontal, vertical and inclined pipes

\begin{tabular}{|c|c|c|c|c|c|}
\hline Correlation & $E_{1}(\%)$ & $E_{2}(\%)$ & $E_{3}(\%)$ & $F_{R P}$ & $R^{2}$ \\
\hline \multicolumn{6}{|l|}{ Horizontal pipes } \\
\hline \multicolumn{6}{|c|}{ First interval- $-\mu \leq 1 \mathrm{cP}$} \\
\hline Zivi [99] & 3.71 & 41.43 & 1897.20 & $6.40 e^{-11}$ & 0.62 \\
\hline Fauske [86] & -23.16 & 43.57 & 1780.70 & $1.64 e^{-10}$ & 0.58 \\
\hline Turner and Wallis [100] & -18.80 & 45.80 & 1710.00 & $1.74 e^{-10}$ & 0.59 \\
\hline Hart et al. [72] & 5.18 & 45.86 & 2185.00 & $7.94 e^{-11}$ & 0.58 \\
\hline Thom [98] & 27.12 & 49.35 & 2849.80 & $3.35 e^{-11}$ & 0.60 \\
\hline \multicolumn{6}{|c|}{ Second interval $-1<\mu \leq 10 \mathrm{CP}$} \\
\hline Homogeneous [87] & -44.23 & 54.03 & 1796.10 & $8.09 e^{-11}$ & 0.73 \\
\hline Zhao et al. [66] & -45.70 & 55.07 & 1748.60 & $8.50 e^{-11}$ & 0.73 \\
\hline Armand [101] and Massena [102] & -47.22 & 55.47 & 1738.00 & $8.77 e^{-11}$ & 0.72 \\
\hline Hart et al. [72] & 8.73 & 57.63 & 2619.50 & $3.37 e^{-11}$ & 0.85 \\
\hline Armand [101] & -53.54 & 61.11 & 1496.20 & $1.08 e^{-10}$ & 0.73 \\
\hline \multicolumn{6}{|c|}{ Third interval $-\mu>10 \mathrm{cP}$} \\
\hline Choi et al. [103] & 8.04 & 27.88 & 841.62 & $7.89 e^{-17}$ & 0.83 \\
\hline Jowitt et al. [104] & 1.63 & 31.46 & 907.57 & $1.14 e^{-16}$ & 0.76 \\
\hline Mattar and Gregory [105] & -2.64 & 31.51 & 879.25 & $1.45 e^{-16}$ & 0.74 \\
\hline Maier and Coddington [87] & -1.30 & 32.10 & 916.23 & $1.12 e^{-16}$ & 0.78 \\
\hline Lockhart and Martinelli [76] & 19.66 & 37.44 & 1158.40 & $2.11 e^{-16}$ & 0.78 \\
\hline \multicolumn{6}{|l|}{ Vertical pipes } \\
\hline \multicolumn{6}{|c|}{ First interval $-\mu \leq 1 \mathrm{cP}$} \\
\hline Premoli et al. [106] & 9.44 & 62.55 & 2618.50 & $9.94 e^{-31}$ & 0.21 \\
\hline Rouhani and Axelsson [93] & 36.77 & 63.71 & 3362.10 & $1.09 e^{-30}$ & 0.46 \\
\hline Choi et al. [103] & 46.30 & 65.85 & 3822.30 & $1.17 e^{-30}$ & 0.53 \\
\hline Zuber and Findlay [82] & 44.51 & 66.71 & 3808.20 & $1.20 e^{-30}$ & 0.51 \\
\hline Bonnecaze et al. [80] & 44.82 & 67.26 & 3852.00 & $1.22 e^{-30}$ & 0.50 \\
\hline \multicolumn{6}{|c|}{ Second interval $-1<\mu \leq 10 \mathrm{cP}$} \\
\hline Guzhov et al. [83] & 23.63 & 52.87 & 2127.70 & $2.29 e^{-37}$ & 0.69 \\
\hline Kokal and Stanislav [79] & 22.21 & 52.92 & 2156.60 & $2.53 e^{-37}$ & 0.70 \\
\hline Bonnecaze et al. [80] & 22.05 & 52.95 & 2155.30 & $2.56 e^{-37}$ & 0.70 \\
\hline Nicklin et al. [81] & 22.02 & 52.96 & 2155.20 & $2.56 e^{-37}$ & 0.70 \\
\hline Premoli et al. [106] & -10.14 & 55.02 & 1513.50 & $1.71 e^{-36}$ & 0.34 \\
\hline \multicolumn{6}{|c|}{ Third interval- $\mu>10 \mathrm{cP}$} \\
\hline Rouhani and Axelsson [93] & 29.94 & 62.45 & 1590.60 & $9.80 e^{-12}$ & 0.44 \\
\hline Neal and Bankoff [91] & 13.05 & 65.08 & 1288.26 & $2.09 e^{-11}$ & 0.14 \\
\hline Guzhov et al. [83] & 51.00 & 67.69 & 2008.39 & $1.41 e^{-12}$ & 0.47 \\
\hline Yashar et al. [88] & 35.25 & 68.35 & 1607.44 & $1.19 e^{-11}$ & 0.29 \\
\hline Hughmark [107] & 56.68 & 68.78 & 2068.44 & $1.50 e^{-12}$ & 0.48 \\
\hline \multicolumn{6}{|l|}{ Inclined pipes } \\
\hline \multicolumn{6}{|c|}{ First interval $-\mu \leq 1 \mathrm{cP}$} \\
\hline Toshiba [97] & -3.03 & 7.71 & 307.81 & $1.70 e^{-14}$ & 0.92 \\
\hline Woldesemayat and Ghajar [1] & 2.22 & 10.25 & $441 y g .45$ & $6.59 e^{-15}$ & 0.93 \\
\hline Greskovich and Cooper [108] & 8.02 & 11.20 & 403.98 & $3.37 e^{-14}$ & 0.91 \\
\hline $\operatorname{Dix}[73]$ & 1.15 & 11.84 & 491.51 & $1.85 e^{-14}$ & 0.92 \\
\hline Hamersma and Hart [94] & -1.67 & 11.89 & 474.65 & $2.91 e^{-14}$ & 0.88 \\
\hline \multicolumn{6}{|c|}{ Third interval $-\mu>10 \mathrm{cP}$} \\
\hline Choi et al. [103] & 1.46 & 23.09 & 824.10 & $7.67 e^{-19}$ & 0.49 \\
\hline Lockhart and Martinelli [76] & 8.65 & 27.66 & 970.57 & $3.17 e^{-18}$ & 0.44 \\
\hline Mattar and Gregory [105] & 9.58 & 29.80 & 1011.10 & $3.93 e^{-18}$ & 0.39 \\
\hline
\end{tabular}


Table 3 (continued)

\begin{tabular}{llllll}
\hline Correlation & $E_{1}(\%)$ & $E_{2}(\%)$ & $E_{3}(\%)$ & $F_{R P}$ & $R^{2}$ \\
\hline Baroczy [75] & -17.60 & 31.42 & 947.53 & $7.25 e^{-18}$ & 0.47 \\
Flanigan [109] & -17.76 & 33.27 & 1063.80 & $6.95 \mathrm{E}-18$ & 0.46 \\
\hline
\end{tabular}
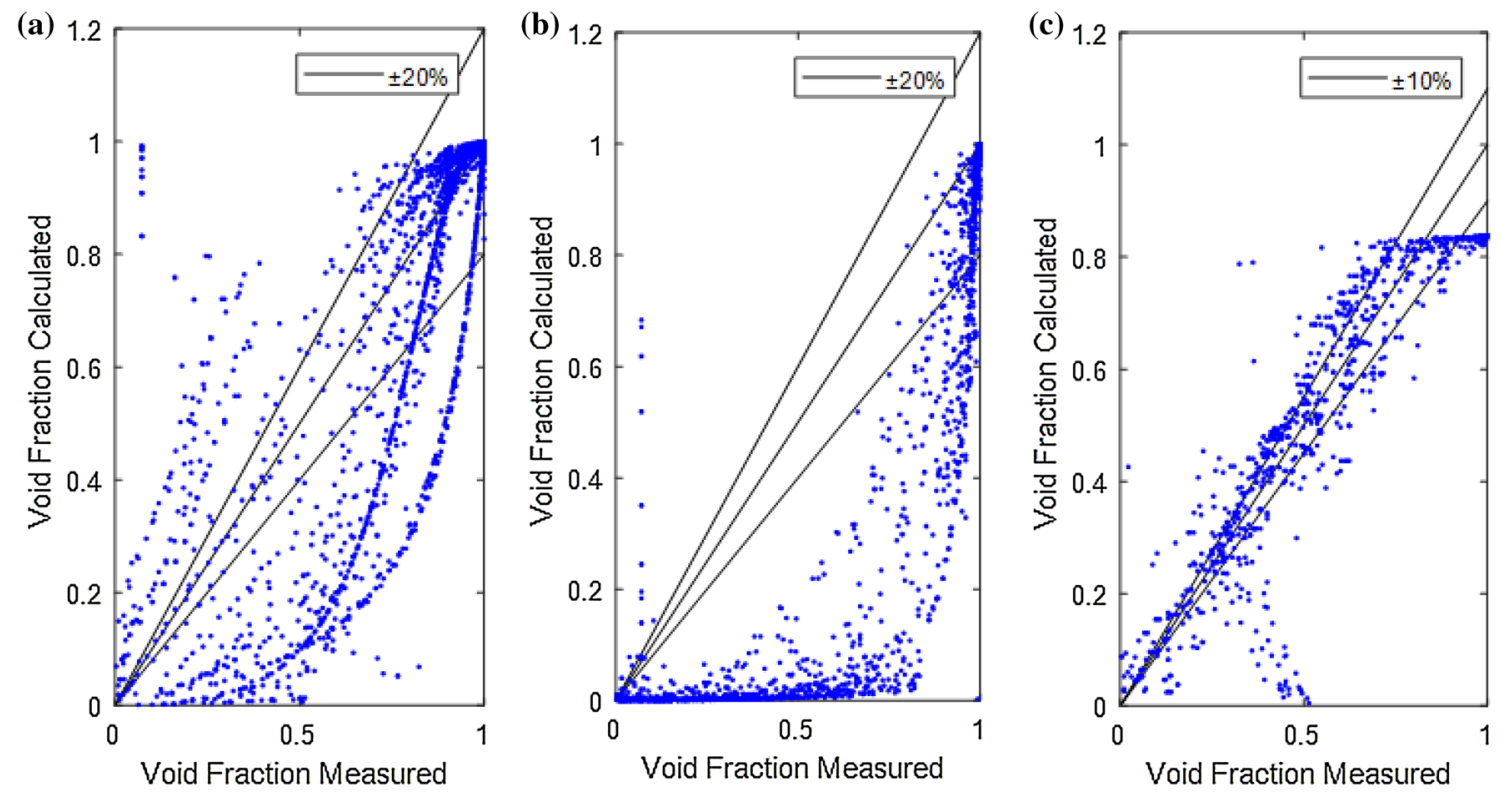

Fig. 9 Results of void fraction for the best correlations on $\mathbf{a} \mu \leq 1$-Zivi [99], $\mathbf{b} 1<\mu \leq 10$-Homogeneous [87] and $\mathbf{c} \mu>10$-Choi et al. [103]

Fig. 10 Distribution of the void fraction calculated within an index error of $20 \%$ for a first viscosity interval and $\mathbf{b}$ second viscosity interval for horizontal pipes

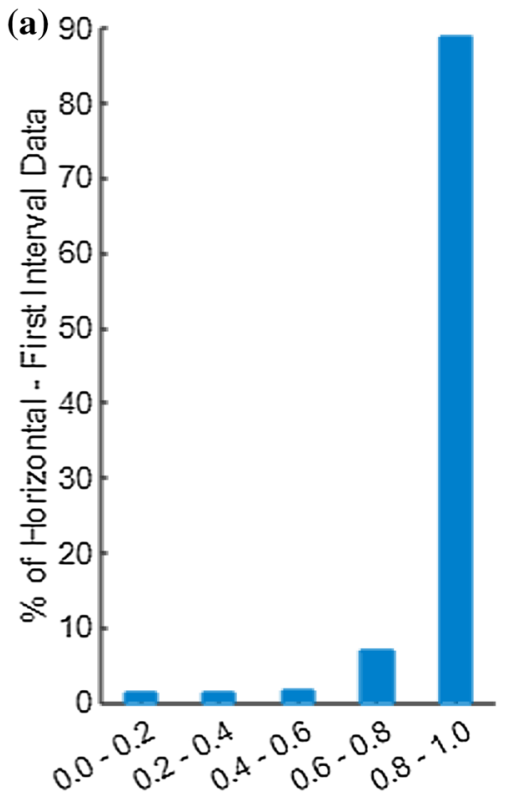

Void Fraction Calculated $\doteq 20 \%$

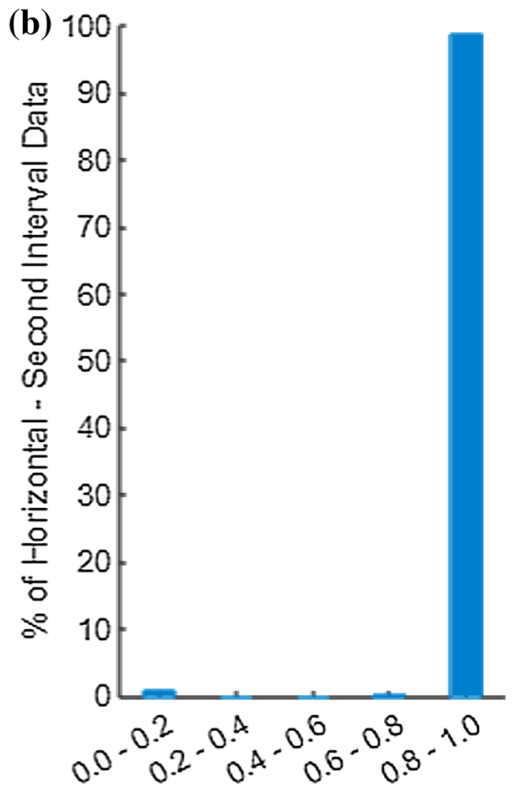

Void Fraction Calculated $\doteq 20 \%$ interval, the homogeneous model only estimated accurately $39 \%$ of the data points with an index error of $\pm 20 \%$; nevertheless, it was possible to evidence a tendency in the data: $89 \%$ of the values estimated reported a quality vapor range between 0.6 and 1.0, as it is shown in Fig. 11. Thus, it is possible to assume that only one phase (gas) exists 

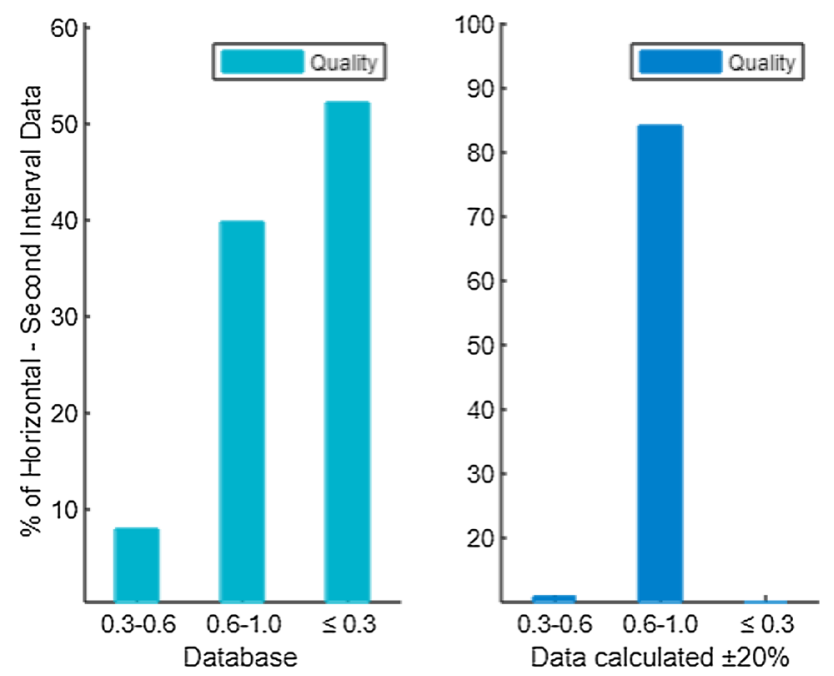

Fig. 11 Distribution of the vapor quality within the datapoint analyzed (left) and estimated (right) in the second viscosity interval for horizontal pipes
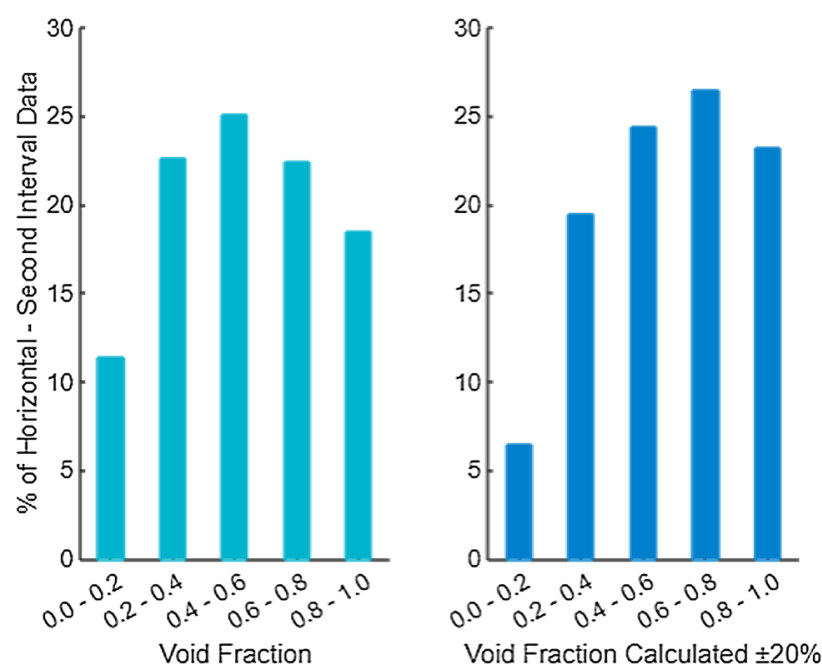

Fig. 12 Distribution of the void fraction values in the data measured (left) and predicted (right) in the third viscosity interval for horizontal pipes

in the system, and that this model represents an accurate estimation.

Choi et al.'s [103] correlation had the best approximation for the third viscosity interval with an estimation of approximately $80 \%$ of the data within an error of $\pm 20 \%$; this is possible because the model includes Reynolds number, which allows the prediction of the void fraction in a wide range of liquid viscosities. Additionally, the authors determined that for high liquid viscosities, the correlation works accurately. Even more, this model can work with the whole range of liquid holdups (0-1), giving a more accurate prediction of lower values, i.e., higher values of void fraction. This can be evidenced in Fig. 12, where the correlation encompasses a wide range of void fraction values, however, in the second and third viscosity intervals, approximately the $99 \%$ of the data points were predicted. On the contrary, in the lowest range, only $45 \%$ were estimated precisely.

From these results, it can be recommended that considerable additional research and improvements should be carried out to develop void fraction correlations that could predict different ranges of liquid viscosities on horizontal pipes, as there is no model with acceptable average absolute percentage error and noticeable deviation was observed.

\subsubsection{Results on vertical pipes}

For vertical pipes, the results of the prediction of the void fraction show a higher deviation in comparison to horizontal pipes, and overpredictions seem to be generalized. In Table 3, the best-performing correlations are depicted in the middle section for vertical pipes. In this case, the best-performing correlations were Guzhov et al. [83] and Rouhani and Axelsson [93] for the intervals $1<\mu \leq 10 \mathrm{cP}$ and $\mu>10 \mathrm{cP}$, respectively. Figure 13 shows the scattering of the calculated void fractions against the database points considered, where it is noticed that for vertical pipes, the correlations are considerably more reliable for liquid viscosities between 1 and $10 \mathrm{cP}$.

Regarding the first interval ( $\mu \leq 1 \mathrm{cP})$, it was essential to separate the results to analyze the best performing correlations. Firstly, it can be seen that, considering the $E_{2}$ parameter, the best correlation obtained is Premoli et al. [106], with a value equal to $62.5 \%$, followed by Rouhani and Axelsson [93], with 63.7\%. This indicates that, in general, all 'best-performing' correlations seem to predict the results with similarly high average deviations (about $60 \%$ ). Consequently, until this point, it can be said that the first correlation may have a better estimation of the data points. Nevertheless, when analyzing the results in Fig. 14a, unphysical negative values are obtained through the correlation, namely $4 \%$ of the total data. Moreover, by analyzing $E_{1}$ values, it can be noticed that Premoli et al.'s [106] correlation has the lowest overprediction. However, in the figures, it seems like an underprediction for values higher than 0.6 exists, opposite to what Woldesemayat [87] exhibited in his study [87], which is that that the model tends to present an excessive overprediction for void fractions lower than 0.8 . Therefore, analyzing this against our data, it can be concluded that the results are in opposition to the behavior expected and, mainly, that $E_{1}$ cannot be considered as a meaningful parameter given that it does not take into account the positive and negative values of 
Fig. 13 Results of void fraction for the best correlations on a $1<\mu \leq 10-$ Guzhov et al. [83], and $\mathbf{b} \mu>10$-Rouhani and Axelsson [93]

Fig. 14 Results of void fraction for the two best correlations for $\mu \leq 1$ : a Premoli et al. [106] and $\mathbf{b}$ Rouhani and Axelsson [93] (a)

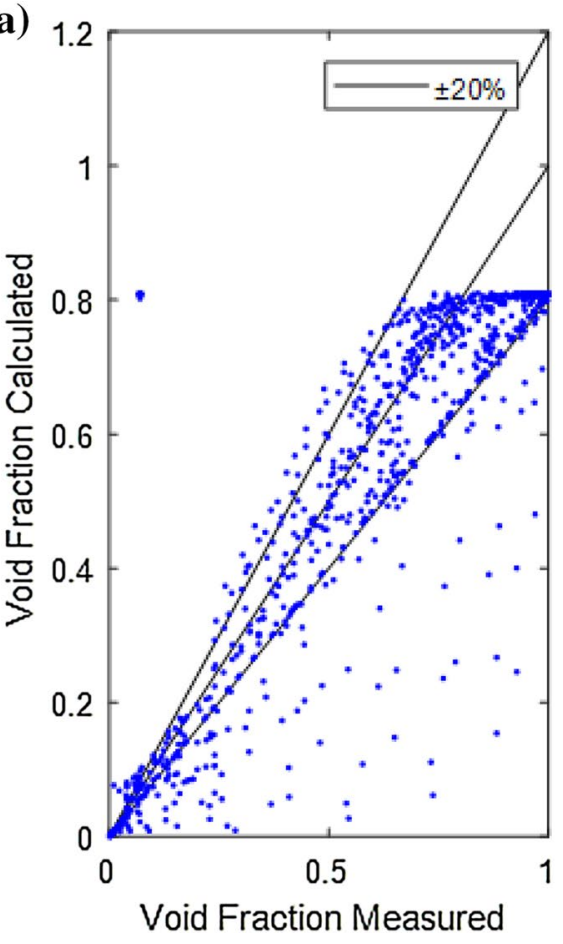

(a)

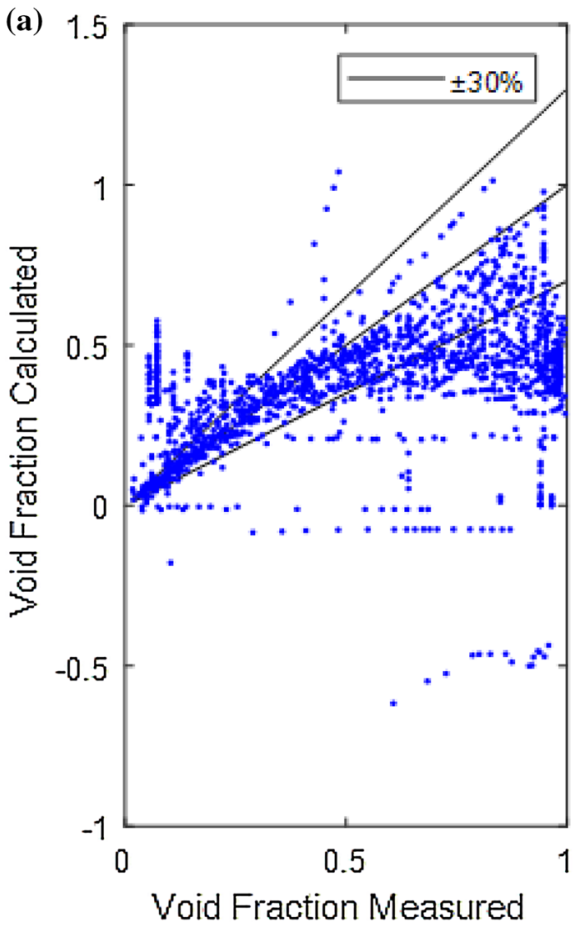

(b)

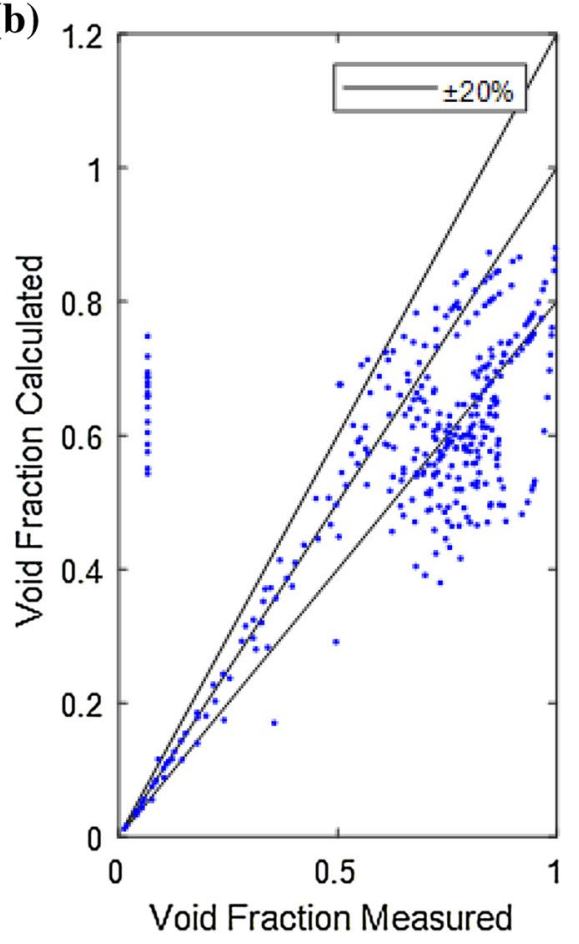

(b)

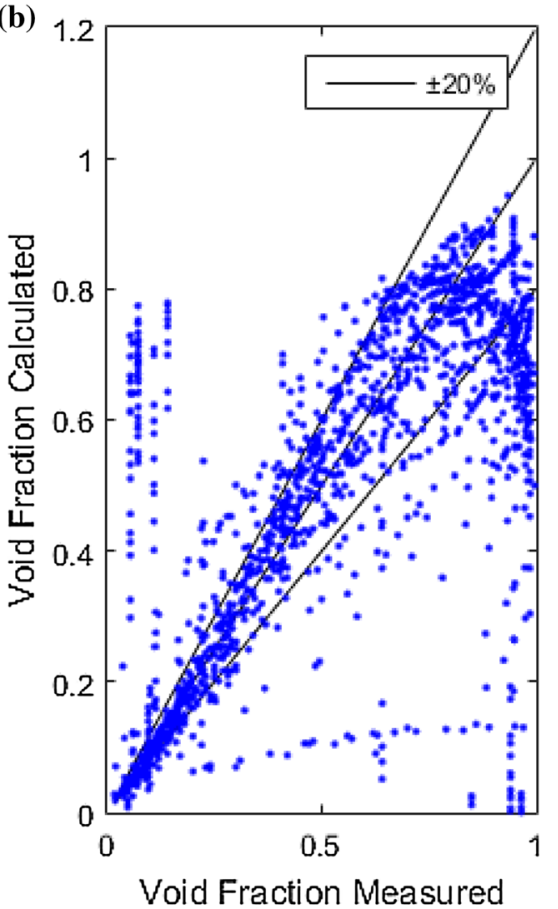

the errors, which could give an inaccurate prediction by canceling some relative errors.

As a consequence of the previous statements, for this first interval ( $\mu \leq 1 \mathrm{cP})$, Rouhani and Axelsson's [93] correlation was considered to be the best approximation, which can be confirmed by the percentage of data calculated within an index error of $\pm 20 \%$ (61\%). Moreover, as it was exposed in Sect. 3.1.2 for vertical pipes, Rouhani and Axelsson's [93] correlation tends to under-predict the values over 0.6, a behavior that is prominent in Fig. 14b, and in tandem, it tends to overpredict values near to zero. In this analysis, a significant under or overprediction is 
noticeable, which can be associated with the fact that this correlation was developed and tested in systems with viscosities higher than $1 \mathrm{cP}$.

Similar to the first interval, the best correlation for the third interval was also Rouhani and Axelsson [93], estimating $50 \%$ of the data within an index error of $\pm 20 \%$, and with a significant average deviation represented by the $E_{2}$ parameter (62\%), almost the same value found for the first interval. Besides, comparing the behavior of the data estimated, in Fig. 13b, the same tendency of either underprediction or overprediction is visible for higher and lower values of void fraction, respectively. Even though this correlation is considered to have accurate predictive capability for these cases, $1<\mu \leq 10 \mathrm{cP}$ and $\mu \leq 1 \mathrm{cP}$ in particular, it does not seem to make acceptable predictions precisely. Moreover, the $\mathrm{R}^{2}$ value shows that very poor fitting is achieved by these models on these viscosity intervals, for which further development and research is suggested to improve the existing models and correct the physical boundaries of the predicted values for these conditions.

As it was stated before, the best approximation for the vertical cases was obtained in the middle interval by Guzhov et al.'s 1967 correlation [83], with $76 \%$ of the data points predicted accurately with an error of $\pm 20 \%$. Nevertheless, this correlation presents an average deviation from the data points of approximately $53 \%$, which is significant to consider these as good estimations. Moreover, a similar behavior to that obtained by Woldesemayat [87] was observed. It was noted that a better prediction is obtained for void fraction values over 0.65 , which in this case consists of almost $90 \%$ of the data points which are in this interval. Finally, a general trend in terms of over and underprediction of the data of this case could not be identified, and similarly to the other two cases, it is suggested as future work to look for a better correlation.

\subsubsection{Results on inclined pipes}

Regarding the inclined pipes, the overall predicted values from the correlations had better accuracy in comparison to the horizontal and vertical pipes, except for the second interval, in which the absolute average error was not included in the results as it was above $100 \%$. Thus, further development of correlations capable of making an accurate prediction on this viscosity interval is suggested.

In this case, the best performing correlations were Toshiba [97] and Choi et al. [103] for the intervals $\mu \leq 1 \mathrm{cP}$ and $\mu>10 \mathrm{CP}$, respectively. In Fig. 17 , the selection of the best correlations for void fraction, considering the different possible inclinations of the pipeline, as well as each of the viscosity ranges analyzed, are observed.

For the first interval, Toshiba [97] could predict 95.2\% of the data within an error of $\pm 20 \%$. This correlation has demonstrated to be able to predict datasets accurately, and to have a consistent performance across a wide range of inclination angles, which agrees with the absolute error obtained of $7.7 \%$. Nevertheless, according to the literature, a slight underprediction is expected for void fractions lower than 0.8, which is generally observed in Fig. 15a, even though some overpredictions are also detected.
Fig. 15 Results of void fraction for the best correlations on a $\mu \leq 1 \mathrm{cP}$-Toshiba [97] and $\mathbf{b}$ $\mu>10$ cP Choi et al. [103]

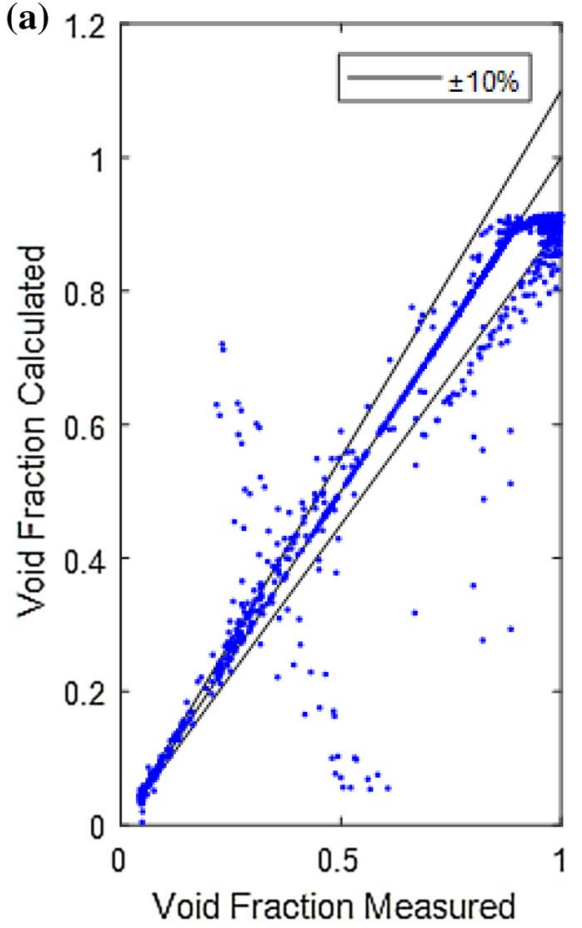

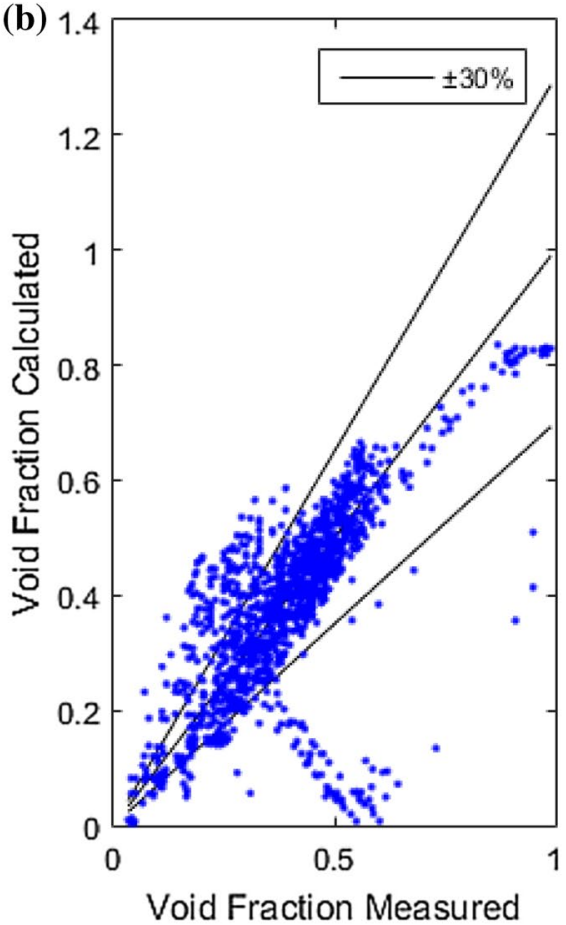

SN Applied Sciences 
For the third viscosity interval, a slightly over-predicting trend can be seen, particularly for the intermediate values of void fractions. This result is reflected in the $E_{1}$ value, where almost all values obtained for the models considered are positive and usually over just $2 \%$. Similarly, as in the horizontal case, this interval of high viscosity was better estimated by Choi et al.'s [103] correlation; namely, $68 \%$ of the total data points were predicted within an index error of $\pm 20 \%$, with an average deviation of $29 \%$. Nonetheless, the correlation had a $12 \%$ decrease in the number of points correctly predicted, compared to the horizontal scenario. This is because, as it was mentioned in Sect. 3.2.1., even though this correlation works in the whole interval of void fraction, it has a more precise estimation for higher values. Almost $51 \%$ of our database for this case lied in the interval between 0 and 0.4 , and only $35 \%$ of this data was predicted within the error expected, unlike for the other intervals from 82 to $90 \%$ of the data which was estimated accurately (Fig. 16). This tendency was also observed in the horizontal case. Therefore, it can be concluded that this correlation has a good estimation in horizontal and inclined pipes for
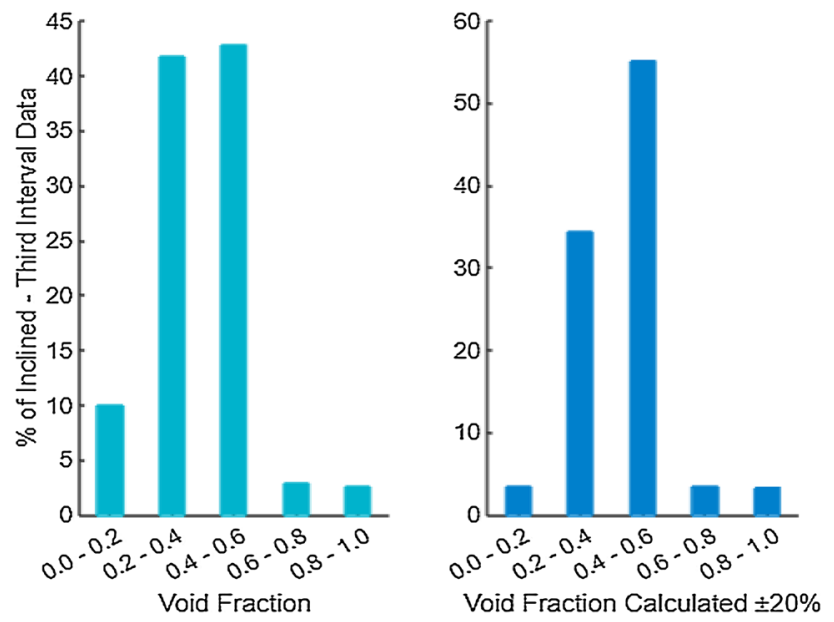

Fig. 16 Distribution of the void fraction values in the data measured (left) and estimated (right) in the third viscosity interval for inclined pipes intervals of viscosities higher than $10 \mathrm{cP}$, only in the range of void fractions higher than 0.5 .

\section{Conclusions}

In this study, a statistical analysis was made for 63 different correlations for the prediction of void fraction for different combinations of pipe inclination, flow pattern, and liquid viscosity range. Consequently, it was possible to suggest the best correlation for a particular operational condition among different formulations, such as Split Ratio, Drift Flux, General, or $K \varepsilon_{H}$. These final void fraction correlations selected for each specific case are summarized in Fig. 17. The selection of the best correlation for each case was rigorously performed by considering various statistical indicators simultaneously and analyzing the graphical dispersion of the experimental data points against their predicted values.

In conclusion, a single correlation that can accurately predict all the cases studied was not found due to the large range of operational conditions, assumptions, flow patterns, and fluid properties that significantly affect the behavior of the void fraction, which is in agreement with previous literature studies. The best approach, as observed, is to model each specific condition with the appropriate correlation that best describes the behavior measured experimentally. For vertical and inclined pipes, drift flux correlations showed the best performance. Moreover, essential findings on correlations with inferior predictive capabilities, unphysical values, and unbounded predictions were found for different cases. The most critical scenarios observed in this study were for the inclined pipelines with churn flow pattern, and inclined liquid viscosities between 1 and $10 \mathrm{cP}$, where the deviations reported were above $100 \%$. Therefore, further research is suggested in the development of void fraction correlations for these particular cases. 

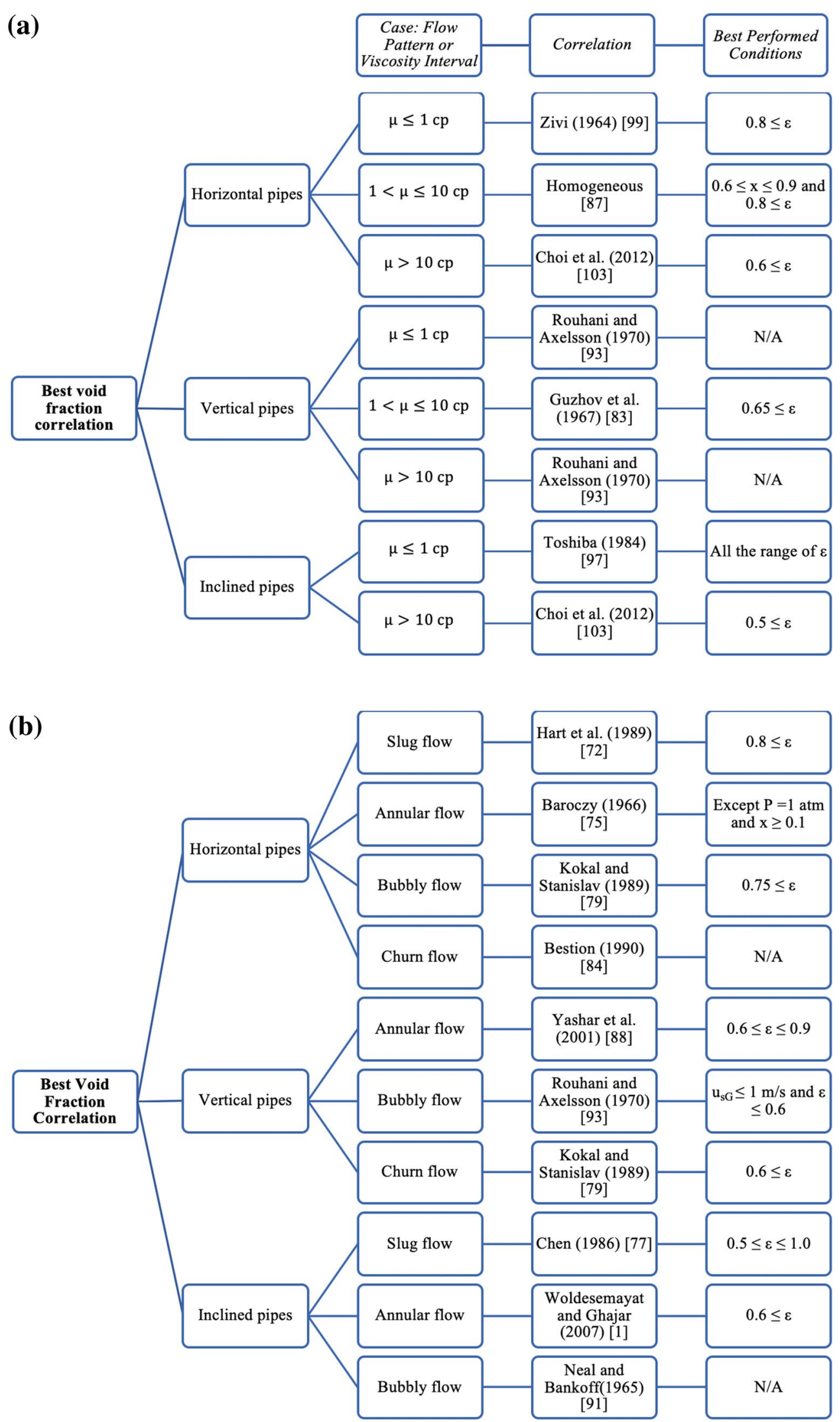

Fig. 17 Summary of the most reliable correlations for the prediction of void fraction according to pipe inclination and: a liquid viscosity and b flow pattern 
Acknowledgements The authors would like to express their gratitude towards the information and technology services management (Dirección de Servicios de Información y Tecnología, DSIT) of Universidad de Los Andes for facilitating the computational resources for the project and their technical support.

\section{Compliance with ethical standards}

Conflict of interest The authors declare that they have no conflict of interest, and no funding sources need to be acknowledged.

\section{References}

1. Woldesemayat MA, Ghajar AJ (2007) Comparison of void fraction correlations for different flow patterns in horizontal and upward inclined pipes. Int J Multiph Flow 33(4):347-370. https ://doi.org/10.1016/j.ijmultiphaseflow.2006.09.004

2. Bhagwat SM, Ghajar AJ (2014) A flow pattern independent drift flux model based void fraction correlation for a wide range of gas-liquid two phase flow. Int J Multiph Flow 59:186-205. https ://doi.org/10.1016/j.ijmultiphaseflow.2013.11.001

3. Thome JR (2004) Engineering data book III. Wolverine Tube, Inc, Decatur

4. Parrales A, Colorado D, Huicochea A, Díaz J, Alfredo Hernández $J \mathrm{~J}$ (2014) Void fraction correlations analysis and their influence on heat transfer of helical double-pipe vertical evaporator. Appl. Energy 127:156-165. https://doi.org/10.1016/j.apene rgy.2014.04.036

5. Godbole PV, Tang CC, Ghajar AJ (2011) Comparison of void fraction correlations for different flow patterns in upward vertical two-phase flow. Heat Transf Eng 32(10):843-860. https://doi. org/10.1080/01457632.2011.548285

6. Wang N, Sun B, Gong P, Wang Z (2016) Improved void fraction correlation for two-phase flow in large-diameter annuli 40(4):745-754

7. Vijayan PK, Patil AP, Pilkhwal DS, Saha D, Venkat Raj V (2000) Assessment of pressure drop and void fraction correlations with data from two-phase natural circulation loops. Heat Mass Transf Stoffuebertrag 36(6):541-548. https://doi.org/10.1007/ s002310000108

8. Mills D (2016) Chapter 2 - Airflow and particle flow in pipelines. In: Pneumatic conveying design guide, 3rd edn. Elsevier Ltd, pp 33-57

9. Amaya-Gomez R et al (2019) Probabilistic approach of a flow pattern map for horizontal, vertical, and inclined pipes. Oil Gas Sci Technol. https://doi.org/10.2516/ogst/2019034

10. Abdulkadir M (2011) Experimental and computational fluid dynamics (CFD) studies of gas-liquid flow in bends. Ph.D. dissertation, vol 262, no August, p 360

11. Adedigba AG (2007) Two-phase flow of gas-liquid mixtures in horizontal helical pipes. Ph.D. thesis, Cranfield University, Wharley End, United Kingdom

12. Aggour MA (1976) Hydrodynamics and heat transfer in twophase two-component flows. Ph.D. thesis, The University of Manitoba, Winnipeg, Manitoba, p 466

13. Agrawal SS, Gregory GA, Govier GW (1973) An analysis of horizontal stratified two phase flow in pipes. Can J Chem Eng 51(3):280-286. https://doi.org/10.1002/cjce.5450510303

14. Alamu MB (2010) Investigation of periodic structures in gasliquid flow. The University of Nottingham, Nottingham

15. Al-lababidi S (2006) Slug closure model. Assessment
16. Almabrok A (2013) Gas-liquid two-phase flow in up and down vertical pipes. Cranfield University, Cranfield

17. Alsaadi Y (2013) Liquid loading in highly deviated gas wells. The University of Tulsa, Tulsa

18. Alssayh MAA (2013) Slug velocity measurement and flow regime recognition using acoustic emission technology, p 185

19. Andritsos N (1986) Effect of pipe diameter and liquid viscosity on horizontal stratified flow, p 224

20. Asante B (2000) Multiphase transport of gas and low loads of liquids in pipelines. University of Calgary, Calgary

21. Govier GW, Aziz KJ (1972) The flow of complex mixtures in pipes. Van Nostrand Reinhold Company, New York

22. Brito R (2012) Effect of medium oil viscosity on two-phase oilgas flow behavior in horizontal pipes. The University of Tulsa, Tulsa

23. Caetano EF (1985) Upward vertical two-phase flow through an annulus. The University of Tulsa, Tulsa

24. Chung S, Pereyra E, Sarica C, Soto G, Alruhaimani F, Kang J (2016) Effect of high oil viscosity on oil-gas flow behavior in vertical downward pipes. In: BHR Group's 12th North American conference on multiphase production technology 2016, pp 259-270

25. Chupin G (2003) An experimental study of multiphase gas-liquid pipe flow at low liquid loading, no September, p 384

26. Ekinci $S$ (2015) Pipe inclination effects on slug flow characteristics of high viscosity oil-gas two-phase flow. The University of Tulsa, Tulsa

27. Faccini JLH, Cunha Filho JS, De Sampaio PAB, Su J (2015) Experimental and numerical investigation of stratified gas-liquid flow in downward-inclined pipes. Heat Transf Eng 36(11):943-951. https://doi.org/10.1080/01457632.2015.972729

28. Fan Y (2005) An investigation of low liquid loading gas-liquid stratified flow in near-horizontal pipes. Ph.D. thesis, The University of Tulsa, Tulsa, USA

29. Fernandez OE (1982) Hydrodynamic model for intermittent gas lifting of viscous oil. The University of Tulsa, Tulsa

30. França F, Lahey RT (1992) The use of drift-flux techniques for the analysis of horizontal two-phase flows. Int J Multiph Flow 18(6):787-801. https://doi.org/10.1016/0301-9322(92)90059 $-\mathrm{P}$

31. Ghajar AJ, Tang CC (2009) Advances in void fraction, flow pattern maps and non-boiling heat transfer two-phase flow in pipes with various inclinations. Adv Multiph Flow Heat Transf $1: 1-52$

32. Gokcal B (2005) Effects of high oil viscosity on two-phase oil-gas flow behavior in horizontal pipes. The University of Tulsa, Tulsa

33. Govier GW, Short WL (1958) The upward vertical flow of airwater mixtures: II. Effect of tubing diameter on flow-pattern, holdup and pressure drop. Can J Chem Eng 36(5):195-202. https://doi.org/10.1002/cjce.5450360501

34. Gregory GA, Nicholson MK, Aziz K (1978) Correlation of the liquid volume fraction in the slug for horizontal gasliquid slug flow. Int J Multiph Flow 4(1):33-39. https://doi. org/10.1016/0301-9322(78)90023-X

35. Griffith P, Wallis GB (1961) Two-phase slug flow. J Heat Transf 83(3):307-318. https://doi.org/10.1115/1.3682268

36. Güler-Quadir N (1991) Two-phase pressure drop and holdup in flow through large diameter vertical tubing. The University of Tulsa, Tulsa

37. Haoulo Mubayed M (2007) Estudio Experimental De Patrones De Flujo Bifásico Gas-Líquido En Tuberías. Universidad Central de Venezuela, Caracas

38. Jeyachandra BC (2011) Effect of pipe inclination on flow characteristics of high flow, viscosity oil-gas two-phase. The University of Tulsa, Tulsa 
39. Karami Hamidreza M (2015) Low liquid loading three-phase flow and effects of meg on flow behavior. The University of Tulsa, Tulsa

40. Kim D, Ghajar AJ, Dougherty RL (2000) Robust heat transfer correlation for turbulent gas-liquid flow in vertical pipes. J Thermophys Heat Transf 14(4):574-578. https://doi. org/10.2514/2.6559

41. Kokal SL (1987) An experimental study of two phase flow in inclined' pipes. The University of Calgary, Calgary

42. Kouba GE (1986) Horizontal slug flow modeling and metering. University of Tulsa, Tulsa

43. Liu D, Wang $S$ (2008) Flow pattern and pressure drop of upward two-phase flow in vertical capillaries. Ind Eng Chem Res 47(1):243-255. https://doi.org/10.1021/ie070901h

44. Lunde O (1997) Detailed measurements of slug flow behaviour in inclined multiphase flow. BHR Group. Multiphase 97:343-368

45. Mantilla I (2008) Mechanistic modeling of liquid entrainment in gas in horizontal pipes. The University of Tulsa, Tulsa

46. da Mata JD (1989) Medida de fração de vazio superficial num escoamento bifásico gas-liquido pela técnica de atenuação de raios gama. DEPARTAMENTO DE ENGENHARIA DE PETROLEO

47. Meng W (1999) Low liquid loading gas-liquid two-phase flow in near horizontal pipes. Ph.D. thesis, The University of Tulsa, Tulsa, USA

48. Mora Vallejo L, Zegrí Reiriz A (2011) A theoretical and experimental study of horizontal air-water. two-phase flow with a spool piece, no July

49. Mukherjee $H$ (1979) An experimental study of inclined twophase flow. Ph.D. thesis, The University of Tulsa, Tulsa, USA

50. Nicholson MK, Aziz K, Gregory GA (1978) Intermittent two phase flow in horizontal pipes: predictive models. Can J Chem Eng 56(6):653-663. https://doi.org/10.1002/cjce.5450560601

51. Nuland S (1997) Gas fractions in slugs in dense-gas two-phase flow from horizontal to 60 degrees of inclination. In: 1997 ASME fluids engineering division summer meeting

52. Nydal OJ, Andreussi P (1991) Gas entrainment in a long liquid slug advancing in a near horizontal pipe. Int J Multiph Flow 17(2):179-189. https://doi.org/10.1016/0301-9322(91)90014-T

53. Rosa ES, Salgado RM, Ohishi T, Mastelari N (2010) Performance comparison of artificial neural networks and expert systems applied to flow pattern identification in vertical ascendant gas-liquid flows. Int J Multiph Flow 36(9):738-754. https://doi. org/10.1016/j.ijmultiphaseflow.2010.05.001

54. Schubring D, Ashwood AC, Shedd TA, Hurlburt ET (2010) Planar laser-induced fluorescence (PLIF) measurements of liquid film thickness in annular flow. Part I: methods and data. Int J Multiph Flow 36(10):815-824. https://doi.org/10.1016/j.ijmultipha seflow.2010.05.007

55. Shanmugam N (1992) Upward cocurrent gas-liquid two-phase flow in vertical tubes. Oklahoma State University, Stillwater

56. Skopich A (2012) Experimental study of surfactant effect on liquid loading in 2-in and 4-in diameter vertical pipes. The Univeristy of Tulsa, Tulsa

57. Smith SP (1999) Experimental investigation of multiple solutions for liquid holdup in upward inclined stratified flow. University of Calgary, Calgary

58. Sujunmnong M (1997) Heat transfer pressure drop and void fraction in two phase, two-component flow in a vertical tube. The University of Manitoba, Winnipeg

59. Tang CC, Tiwari S, Ghajar AJ (2013) Effect of void fraction on pressure drop in upward vertical two-phase gas-liquid pipe flow. J Eng Gas Turbines Power 135(2):1-7. https://doi. org/10.1115/1.4007762
60. Vieira RE et al (2015) Experimental characterization of vertical gas-liquid pipe flow for annular and liquid loading conditions using dual wire-mesh sensor. Exp Therm Fluid Sci 64:81-93. https://doi.org/10.1016/j.expthermflusci.2015.02.007

61. Vijay MM (1977) A study of heat transfer in two-phase twocomponent flow in a vertical tube. The University of Manitoba, Winnipeg

62. Vongvuthipornchai S (1982) Experimental study of pressure wave propagation in two-phase mixtures. The University of Tulsa, Tulsa

63. Wang G, Ching CY (2001) Measurement of multiple gas-bubble velocities in gas-liquid flows using hot-film anemometry. Exp Fluids 31(4):428-439. https://doi.org/10.1007/s003480100326

64. Xu JY, Wu YX (2009) A simple model for predicting the void fraction of gas/non-newtonian fluid intermittent flows in upward inclined pipes. Chem Eng Commun 196(6):746-753. https:// doi.org/10.1080/00986440802557401

65. Yuan G (2011) Liquid loading of gas wells. The University of Tulsa, Tulsa

66. Zhao HD, Lee KC, Freeston DH (2000) Geothermal two-phase flow in horizontal pipes. In: Proceedings world geothermal congress 2000, p 5

67. Zhu W (2003) An investigation of two-phase flow regime transition in large diameter pipes, p 145

68. Shoham O (2006) Mechanistic modeling of gas-liquid twophase flow in pipes, Edición. Society of Petroleum Engineers, Richardson, TX

69. Ansari AM, Sylvester ND, Sarica C, Shoham O, Brill JP (1994) A comprehensive mechanistic model for upward two-phase flow in wellbores. SPE Prod Facil 9(02):143-151. https://doi. org/10.2118/20630-PA

70. Hao M, Lin Y, Zhao X (2016) A relative error-based approach for variable selection. Comput Stat Data Anal 103:250-262. https ://doi.org/10.1016/j.csda.2016.05.013

71. Hibiki T, Mao K, Ozaki T (2017) Development of void fractionquality correlation for two-phase flow in horizontal and vertical tube bundles. Prog Nucl Energy. https://doi.org/10.1016/j. pnucene.2017.01.003

72. Hart J, Hamersma PJ, Fortuin JMH (1989) Correlations predicting frictional pressure drop and liquid holdup during horizontal gas-liquid pipe flow with a small liquid holdup. Int J Multiph Flow 15(6):947-964. https://doi.org/10.1016/03019322(89)90023-2

73. Dix GE (1971) Vapor void fractions for forced convection with subcooled boiling at low flow rates. Ph.D. thesis, University of California, Berkeley

74. Minami K, Brill JP (1987) Liquid holdup in wet-gas pipelines. SPE Prod Eng 2(01):36-44. https://doi.org/10.2118/14535-PA

75. Baroczy CJ (1966) Systematic correlation for two-phase pressure drop. Chem Eng Prog Symp Ser 62(64):232-249

76. Lockhart RW, Martinelli RC (1949) Proposed correlation of data for isothermal two-phase, two-component flow in pipes. Chem Eng Prog 45(1):39-48

77. Chen JJJ (1986) A further examination of void fraction in annular two-phase flow. Int J Heat Mass Transf 29(11):17601763. https://doi.org/10.1016/0017-9310(86)90116-X

78. Chisholm D (1985) Two-phase flow in heat exchangers and pipelines. Heat Transf Eng 6(2):48-57. https://doi. org/10.1080/01457638508939624

79. Kokal SL, Stanislav JF (1989) An experimental study of twophase flow in slightly inclined pipes-II. Liquid holdup and pressure drop. Chem Eng Sci 44(3):681-693. https://doi. org/10.1016/0009-2509(89)85043-2

80. Bonnecaze RH, Erskine W, Greskovich EJ (1971) Holdup and pressure drop for two-phase slug flow in inclined pipelines. 
AIChE J 17(5):1109-1113. https://doi.org/10.1002/aic.69017 0516

81. Nicklin DJ, Wilkes JO, Davidson J (1962) Two-phase flow in vertical tubes. Chem Eng Sci 40(8):61-68. https://doi. org/10.1016/0009-2509(62)85027-1

82. Zuber N, Findlay JA (1965) Average volumetric concentration in two-phase flow systems. J Heat Transf 87(4):453-468. https ://doi.org/10.1115/1.3689137

83. Guzhov Al, Mamaev VA, Odishariia GE (1967) A study of transportation in gas-liquid systems. International Gas Union, Barcelona

84. Bestion D (1990) The physical closure laws in the CATHARE code. Nucl Eng Des 124(3):229-245. https://doi. org/10.1016/0029-5493(90)90294-8

85. Kataoka I, Ishii M (1987) Drift flux model for large diameter pipe and new correlation for pool void fraction. Int J Heat Mass Transf 30(9):1927-1939. https://doi.org/10.1016/00179310(87)90251-1

86. Fauske H (1961) Critical two-phase, steamwater flows. In: Proceedings of the 1961, heat transfer and fluid mechanics institute. Stanford University Press, Stanford, CA, USA, pp 79-89

87. Woldesemayat MA (2006) Comparison of void fraction correlations for two-phase flow in horizontal and upward inclined flows. M.Sc. thesis, Oklahoma State University, Oklahoma, USA

88. Yashar DA, Wilson MJ, Kopke HR, Graham DM, Chato JC, Newell TA (2001) An investigation of refrigerant void fraction in horizontal, microfin tubes. In: ASHRAE transactions, vol 107 PART 2, pp 173-188

89. Dimentiev BA, Lepilin RS, Loginov AA (1959) An investigation of hydrodynamic process of bubbling through a vapor liquid mixture of considerable height. Nauch Dokl Vish Shkol-Energ 2:251

90. Petalas N, Aziz K (1997) A mechanistic model for stabilized multiphase flow in pipes. Stanford University, Stanford, CA

91. Neal LG, Bankoff SG (1965) Local parameters in cocurrent mercury-nitrogen flow: parts I and II. AIChE J 11(4):624-635. https ://doi.org/10.1002/aic.690110413

92. Filiminov Al, Przhizhalovski MM, Dik EP, Petrova JN (1957) The driving head in pipes with a free interface in the pressure range from 17 to $180 \mathrm{~atm}$. Teploenergetika 4:22-26

93. Rouhani SZ, Axelsson E (1970) Calculation of void volume fraction in the subcooled and quality boiling regions. Int J Heat Mass Transf 13(2):383-393. https://doi.org/10.1016/00179310(70)90114-6

94. Hamersma PJ, Hart J (1987) A pressure drop correlation for gas/liquid pipe flow with a small liquid holdup. Chem Eng Sci 42(5):1187-1196. https://doi.org/10.1016/0009-2509(87)80068 $-4$

95. Wallis GB (1969) One-dimensional two-phase flow. McGrawHill, New York
96. Spedding PL, Chen JJJ (1984) Holdup in two phase flow. Int J Multiph Flow 10(3):307-339. https://doi.org/10.1016/03019322(84)90024-7

97. Coddington P, Macian R (2002) A study of the performance of void fraction correlations used in the context of drift-flux twophase flow models. Nucl Eng Des 215(3):199-216. https://doi. org/10.1016/S0029-5493(01)00503-9

98. Thom JRS (1964) Prediction of pressure drop during forced circulation boiling of water. Int J Heat Mass Transf 7(7):709-724. https://doi.org/10.1016/0017-9310(64)90002-X

99. Zivi SM (1964) Estimation of steady-state steam void-fraction by means of the principle of minimum entropy production. $J$ Heat Transf 86(2):247-251. https://doi.org/10.1115/1.3687113

100. Turner JM, Wallis GB (1965) The separate-cylinders model of two-phase flow. Ph.D. thesis, Thayer's School Eng, Dartmouth College, Hanover, USA

101. Armand AA (1946) The resistance during the movement of a two-phase system in horizontal pipes. Atomic Energy Research Establishment, Dhaka

102. Massena WA (1960) Steam-water pressure drop and critical discharge flow-a digital computer program. Hanford Atomic Products Operation, Richland

103. Choi J, Pereyra E, Sarica C, Park C, Kang JM (2012) An efficient drift-flux closure relationship to estimate liquid holdups of gas-liquid two-phase flow in pipes. Energies 5(12):5294-5306. https://doi.org/10.3390/en5125294

104. Jowitt D, Cooper CA, Pearson KG (1984) The THETIS $80 \%$ blocked cluster experiment. Part 5. UKAEA Atomic Energy Establishment, AEEW-R-1767, Dhaka

105. Mattar L, Gregory GA (1974) Air-oil slug flow in an upwardinclined pipe-l: slug velocity, holdup and pressure gradient. J Can Pet Technol 13:11. https://doi.org/10.2118/74-01-07

106. Premoli A, Francesco D, Prima A (1970) An empirical correlation for evaluating two-phase mixture density under adiabatic conditions. In: European Two-Phase Flow Group Meeting, Milan, Italy

107. Hughmark GA (1962) Holdup in gas-liquid flow. Elsevier Sci 58(4):62-65

108. Greskovich EJ, Cooper WT (1975) Correlation and prediction of gas-liquid holdups in inclined upflows. AIChE J 21(6):11891192. https://doi.org/10.1002/aic.690210619

109. Flanigan O (1958) Effect of uphill flow on pressure drop in design of two-phase gathering systems. Oil Gas J 56(3):132-141

Publisher's Note Springer Nature remains neutral with regard to jurisdictional claims in published maps and institutional affiliations. 